ARTICLE

DOI: $10.1038 / \mathrm{s} 41467-018-03272-2$

\title{
Accumbens dopamine D2 receptors increase motivation by decreasing inhibitory transmission to the ventral pallidum
}

\author{
Eduardo F. Gallo1,2, Jozsef Meszaros², Jeremy D. Sherman ${ }^{1,2}$, Muhammad O. Chohan (1) ${ }^{3}$, Eric Teboul ${ }^{1,2}$, \\ Claire S. Choi ${ }^{1,2}$, Holly Moore ${ }^{1,3}$, Jonathan A. Javitch (i) ${ }^{1,2,4} \&$ Christoph Kellendonk ${ }^{1,2,4}$
}

Dopamine D2 receptors (D2Rs) in the nucleus accumbens (NAc) regulate motivated behavior, but the underlying neurobiological mechanisms remain unresolved. Here, we show that selective upregulation of D2Rs in the indirect pathway of the adult NAc enhances the willingness to work for food. Mechanistic studies in brain slices reveal that D2R upregulation attenuates inhibitory transmission at two main output projections of the indirect pathway, the classical long-range projections to the ventral pallidum (VP), as well as local collaterals to direct pathway medium spiny neurons. In vivo physiology confirms the reduction in indirect pathway inhibitory transmission to the VP, and inhibition of indirect pathway terminals to VP is sufficient to enhance motivation. In contrast, D2R upregulation in the indirect pathway does not disinhibit neuronal activity of the direct pathway in vivo. These data suggest that D2Rs in ventral striatal projection neurons promote motivation by weakening the canonical output to the ventral pallidum.

\footnotetext{
${ }^{1}$ Department of Psychiatry, College of Physicians and Surgeons, Columbia University, New York, NY 10032, USA. ${ }^{2}$ Division of Molecular Therapeutics, New York State Psychiatric Institute, New York, NY 10032, USA. ${ }^{3}$ Division of Integrative Neuroscience, New York State Psychiatric Institute, New York, NY 10032, USA. ${ }^{4}$ Department of Pharmacology, College of Physicians and Surgeons, Columbia University, New York, NY 10032, USA. Correspondence and requests for materials should be addressed to C.K. (email: ck491@cumc.columbia.edu)
} 
M otivational abnormalities are observed in psychiatric disorders including depression, schizophrenia, attention-deficit hyperactivity disorder (ADHD) and substance abuse. A core deficit of these disorders, motivational dysfunction is disruptive to everyday life and in many cases cannot be treated ${ }^{1,2}$.

The nucleus accumbens (NAc) and its dopaminergic innervation are particularly critical for motivated behavior, and pharmacological studies implicate striatal dopamine receptors in the regulation of incentive motivation ${ }^{3,4}$. Antagonists for D1-like and D2-like receptors delivered to the NAc decrease the willingness to work for rewards ${ }^{5}$. Rather than affecting the hedonic value of the reward, it has been suggested that NAc dopamine promotes behavioral activation by regulating effort-related processes and overcoming work-related response $\operatorname{costs}^{3,6-8}$. In line with these observations in animal models, abnormalities in striatal D2 receptor (D2R) levels have been consistently observed in human disorders with altered motivation including addiction, schizophrenia and $\mathrm{ADHD}^{9-16}$. Moreover, higher D2R binding in left striatum relative to the right striatum has been associated with higher incentive motivation ${ }^{17}$.

In a recent behavioral study, we demonstrated that overexpression of postsynaptic D2Rs in the mouse NAc increased motivation without altering consummatory behavior, the representation of the value of the reinforcer, or the ability to flexibly use reward-associated cues ${ }^{18}$. Yet, the cellular and neurophysiological mechanisms by which dopamine D2Rs regulate motivated behavior remain unclear. A critical barrier in the study of D2R function in the NAc has been that D2Rs are expressed in multiple cell types including medium spiny neurons (MSNs), cholinergic interneurons (CINs), as well as on terminals of dopaminergic neurons. Therefore, strategies that enable selective manipulation of D2Rs in relevant cell populations are uniquely suited to identifying cell-specific roles of D2Rs in motivation and to interrogate the consequences of D2R function on basal ganglia circuitry underlying motivated behavior. For this purpose, we recently developed an adeno-associated virus (AAV)-based approach that, in contrast to our initial study ${ }^{18}$, allows selective overexpression of D2Rs in the striatal output pathway of the adult NAc core that endogenously express D2Rs, the indirect pathway $\left(\text { D2R-OE } \text { NAcInd }_{\text {mice }}\right)^{19}$.

The indirect pathway is one of the two main output pathways of the striatum. The indirect pathway expresses D2Rs and modulates the internal segment of the globus pallidus (GPi) and the substantia nigra pars reticulata $(\mathrm{SNr})$ output nuclei through a polysynaptic circuit via the external segment of the GP $(\mathrm{GPe})^{20}$. In contrast, the direct pathway predominantly expresses D1Rs and not D2Rs. It projects monosynaptically to the basal ganglia output nuclei of the GPi and the SNr, but also innervates the "indirect" GPe via bridging collaterals ${ }^{21,22}$. The direct and indirect pathways exert opposing effects on thalamo-cortical activation and are therefore often referred to as "Go" and "NoGo" pathway, respectively. This opposing function has been historically studied in the context of motor regulation and Parkinson's disease $^{23}$. Within the dorsomedial striatum, artificial stimulation of the direct pathway promotes locomotion, whereas activation of the indirect pathway inhibits locomotion ${ }^{8,22,24}$. Nevertheless, both pathways are activated during movement initiation ${ }^{25}$.

Within the ventral striatum, analogous direct and indirect pathways have also been described ${ }^{26-28}$. Like dorsal striatal D2Rexpressing MSNs (D2-MSNs) that innervate the GPe, NAc D2MSNs project to the ventral pallidum (VP). However, recent work suggests that the ventral striatal output pathways are less segregated than those of the dorsal striatum since ventral striatal D1expressing MSNs (D1-MSNs) of the "direct" pathway robustly innervate the VP, in contrast to the less extensive innervation of the GPe by dorsal striatal D1-MSNs ${ }^{29}$. Despite this relative difference in architecture, opposing functions of D1R versus D2Rexpressing ventral striatal pathways have been described. For example, while NAc D1-MSNs have been shown to promote psychostimulant sensitization, conditioned place preference, and self-administration, D2-MSNs of the indirect pathway generally inhibit these behaviors ${ }^{30-33}$. Thus, we also refer to D1-MSNs and D2-MSNs in the NAc as direct pathway and indirect pathway neurons, respectively.

In dopamine neurons, presynaptic D2-autoreceptors are thought to inhibit dopamine release via $\mathrm{G}_{\beta \gamma}$-mediated inhibition of voltage-gated calcium channels and activation of Kv1.2 potassium channels ${ }^{34-36}$. Likewise, slice physiology studies have shown that pharmacological activation of D2Rs reduces inhibitory transmission at the two main outputs of the indirect pathway, intra-striatal collaterals and striatopallidal synapses ${ }^{37-40}$.

Here, we find that selective upregulation of D2Rs in the indirect pathway of the NAc enhances the willingness to work for food in a progressive ratio (PR) task. Using in vitro slice recordings, we find that this increase in motivation is associated with decreased inhibitory transmission from D2-MSNs, resulting in decreased collateral inhibition of direct pathway MSNs within the NAc and in blunted indirect pathway output from the NAc to the VP. However, despite a pronounced decrease in collateral inhibition in the slice after D2-MSN stimulation, D1-MSNs are not more active during the PR task than in control mice, suggesting that collateral inhibition during the PR task may not be strong enough to influence direct pathway activity. In contrast, in vivo recordings of $\mathrm{VP}$ activity following cortical stimulation reveals a decrease in VP inhibition upon D2R upregulation. Moreover, using pathway-specific expression of a designer receptor in vivo, we show that inhibition of synaptic transmission from the indirect pathway to the VP is sufficient to enhance motivated behavior. These findings suggest that D2Rs in NAc D2MSNs regulate motivated behavior by disinhibiting the ventral pallidum.

\section{Results}

D2R upregulation in NAc D2-MSNs increases motivation. We selectively targeted NAc D2-MSNs by bilaterally injecting Credependent adeno-associated viruses (AAVs) expressing either D2R-IRES-mVenus or EGFP into the NAc core of Drd2-Cre mice. We previously demonstrated that this strategy results in a three-fold increase in D2R radioligand binding in NAc membranes ${ }^{19}$. Upregulation was essentially restricted to D2-MSNs, with very limited transgene expression in cholinergic interneurons ( 1 out of $20 \mathrm{ChAT}+$ neurons) ${ }^{19}$. We further observed that viral-mediated D2R expression was specific to the indirect projection pathway, as mVenus or D2R immunoreactive terminals were observed exclusively in the projection target of NAc D2-MSNs, the VP, but not in the substantia nigra pars reticulata (Fig. 1a).

To assess the effect of $\mathrm{D} 2 \mathrm{R}$ upregulation on the willingness of mice to work for a food reward, we used a progressive ratio (PR) task, in which the lever press requirement doubled with each successive reward earned. Mice expressing EGFP (EGFP $\left.{ }_{\mathrm{NAcInd}}\right)$ or overexpressing D2R (D2R-OE NAcInd $_{\text {) in }}$ D2-MSNs underwent operant training 4 weeks after surgery using a continuous reinforcement (CRF) schedule, followed by fixed interval (FI) training prior to PR testing. The groups did not differ in performance on either $\operatorname{CRF}(t=0.68, p=0.51)$ or on any FI schedule tested (Fig. 1b, all ps $>0.05$ ), suggesting that D2R upregulation does not impact operant training.

In the PR task, a survival analysis of the percentage of mice that continue to respond as a function of time revealed that, compared 
a
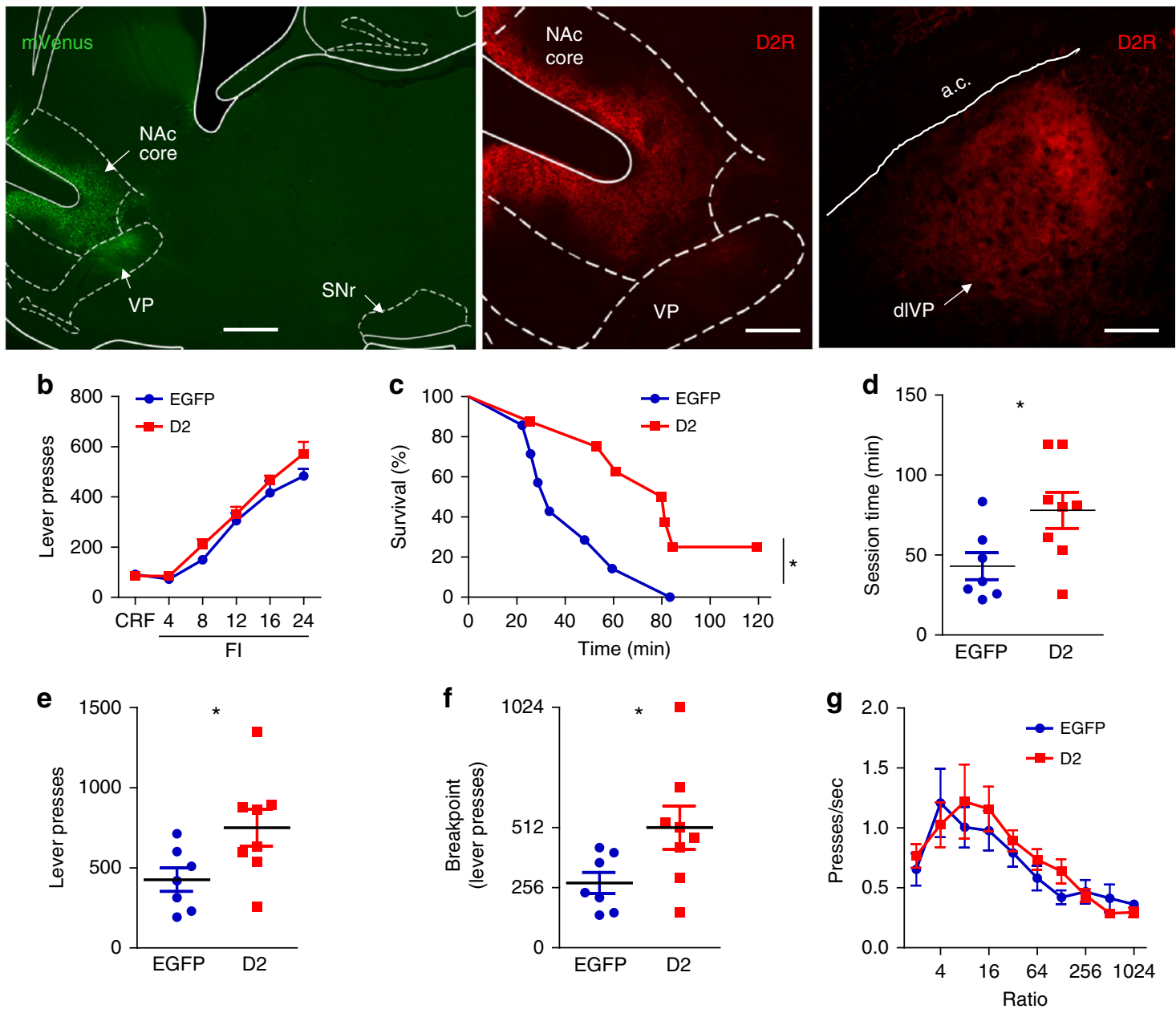

h

NO CHOICE

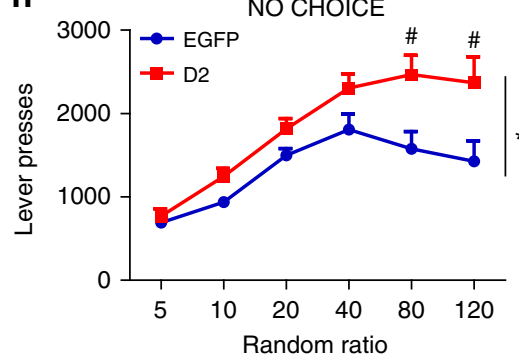

i

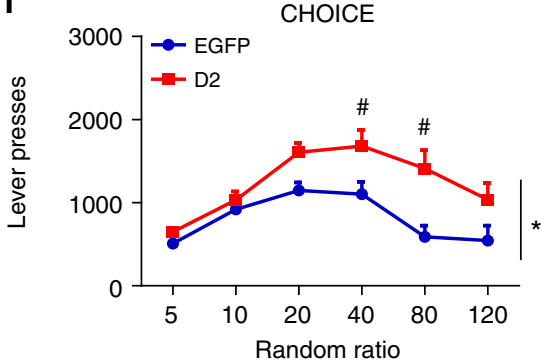

Fig. 1 D2R upregulation enhances motivated behavior. a (Left) Sagittal image of a Drd2-Cre mouse showing that virus-mediated expression ( $m$ Venus) is largely restricted to neurons in the NAc core. mVenus-positive terminal fields are observed in the VP, but not the SNr. Scale $=500 \mu m$. (Middle) Higher magnification image shows increased D2R immunolabeling in the NAc core and in the VP. Scale $=250 \mu$ m. (Right) Coronal view of viral D2R-positive terminal fields in the dorsolateral VP (dIVP). Scale $=150 \mu \mathrm{m}$. b D2R overexpression did not alter operant learning on continuous reinforcement (CRF) schedules or performance on fixed interval (FI) schedules conducted prior to progressive ratio (PR) testing. c Kaplan-Meier survival function showing the percentage of mice that continues to respond on the PR schedule as a function of session time. D2R-OE $E_{N A c I n d}$ mice continue to respond significantly longer

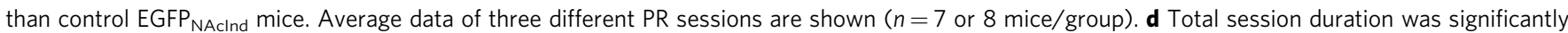

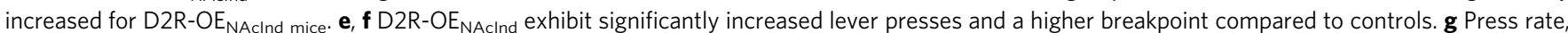
plotted here as a function of the ratio requirement, was unaltered. $\mathbf{h}$ In a random ratio (RR) schedule without concurrent food presentation (NO $\mathrm{CHOICE}$ ), D2R-OE $E_{N A c I n d}$ mice showed significantly higher lever-pressing than controls ( $n=7$ mice/group). i When a freely-available, standard chow was simultaneously presented (CHOICE), D2R-OE $E_{N A c I n d}$ mice continued to press significantly more than controls. Error bars =s.e.m.

to $\mathrm{EGFP}_{\mathrm{NAcInd}}$ controls, D2R-OE $\mathrm{NAcInd}$ mice responded for a significantly longer time $\left(\chi^{2}=4.631, p<0.05\right.$, Log-rank test;

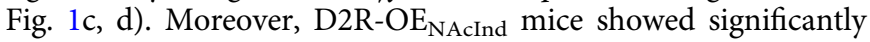
increased lever pressing $(t=2.309, p<0.05, n=7-8$ /group) and a higher breakpoint ( $t=2.188, p<0.05, n=7-8$ /group; Fig. 1e, f).
In contrast, the press rate was not altered in $\mathrm{D} 2 \mathrm{R}-\mathrm{OE}_{\mathrm{NAcInd}}$ mice (Fig. 1g).

To determine whether the small subset of cholinergic interneurons that overexpress D2Rs in the Drd2-Cre line might contribute to these effects ${ }^{19}$, we used the same approach using ChAT-Cre mice. D2R overexpression selectively in cholinergic 
interneurons did not alter PR performance (Supplementary Fig. 1). These results indicate that $\mathrm{D} 2 \mathrm{R}$ upregulation in indirect pathway projection neurons of the NAc core is sufficient to enhance the willingness to work for a reward.

We also evaluated the impact of D2R upregulation on effortrelated decision-making using a concurrent choice task ${ }^{3,18}$. This paradigm measures the animals' choice to work for a preferred reward (evaporated milk) when simultaneously presented with a less preferred but freely accessible reward (chow). When no chow

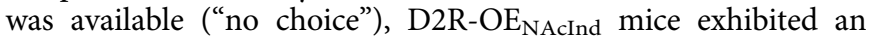
overall increase in responding to the increasing ratio requirements compared to controls $\left(F_{(1,12)}=8.792, p<0.05\right)$ (Fig. 1h). There was also an interaction of $\mathrm{D} 2 \mathrm{R}$ upregulation with work requirement $\left(F_{(5,60)}=3.179, p<0.05\right)$. This effect was particularly prominent at the highest ratio requirements RR80 and RR120 (Bonferroni post hoc test, $p<0.01$ ), where D2R upregulation led to higher responding compared to EGFP. As expected, when chow was freely available in the operant chamber ("choice"), both groups showed a reduction in responding compared to the "nochoice" setting, especially at the more demanding ratio requirements (Fig. 1i). A 2-way ANOVA further indicates that, in the

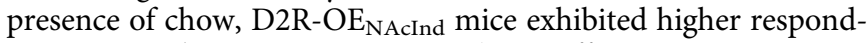
ing compared to $\mathrm{EGFP}_{\mathrm{NAcInd}}$ mice (virus effect: $F_{(1,12)}=8.851, p$ $<0.05$; virus $\times$ ratio interaction: $\left(F_{(5,60)}=3.302, p<0.05\right)$. EGFP $_{\text {NAcInd }}$ mice reduced their responding sooner than the $\mathrm{D} 2 \mathrm{R}-\mathrm{OE}_{\mathrm{NAcInd}}$ mice and the performance difference between the two groups was measurable at a lower ratio when free food was available (RR40, Bonferroni post hoc test: $p<0.05$ ) compared to RR80 in the "no-choice" setting. Together with the PR data, these results suggest that increased $\mathrm{D} 2 \mathrm{R}$ levels in accumbal indirect pathway MSNs promote incentive motivation.

D2R upregulation in D2-MSNs reduces inhibition of D1MSNs. To identify neuronal mechanisms by which D2R upregulation enhances motivation we turned to whole cell patch clamp recordings in NAc slices. Due to the proposed role of presynaptic D2Rs in regulating transmitter release, we examined whether D2R upregulation affects the functional output of D2MSNs. D2-MSNs extend local inhibitory axon collaterals to D1MSNs of the direct pathway ${ }^{38,40-44}$. To determine the impact of D2R upregulation on D2-to-D1-MSN collateral transmission, we co-expressed channelrhodopsin-2 (ChR2) and D2R or EGFP in D2-MSNs. About $84 \%$ of ChR2 positive neurons co-expressed D2R-IRES-Venus, and we confirmed that the ability to induce action potentials by ChR2 activation in D2-MSNs was similar between groups (Supplementary Figs. 2 and 3). Optically-evoked inhibitory postsynaptic currents (oIPSCs) were recorded from the non-fluorescent, D1-MSN-enriched MSN population following photostimulation of D2-MSNs (Fig. 2a). In both groups of animals, we measured oIPSCs that were blocked by the $\mathrm{GABA}_{\mathrm{A}}$ receptor antagonist bicuculline $(10 \mu \mathrm{M})$ (Fig. 2b). Notably, we found that the peak amplitude of the oIPSCs was dramatically

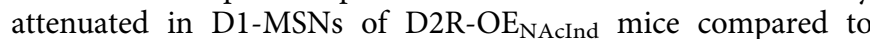
EGFP controls (51.1 \pm 10.9 vs. $273.1 \pm 51.6 \mathrm{pA} ; t=4.709, p<$ 0.0001, $n=$ EGFP: 11(6), D2: 14(9) cells/group) (Fig. 2b, c). Moreover, while the D2R agonist quinpirole $(1 \mu \mathrm{M})$ attenuated the oIPSC in over $90 \%$ of recorded neurons in both $\mathrm{EGFP}_{\text {NAcInd }}$ and $\mathrm{D} 2 \mathrm{R}-\mathrm{OE}_{\mathrm{NAcIn}}$ mice, the extent of quinpirole-mediated a

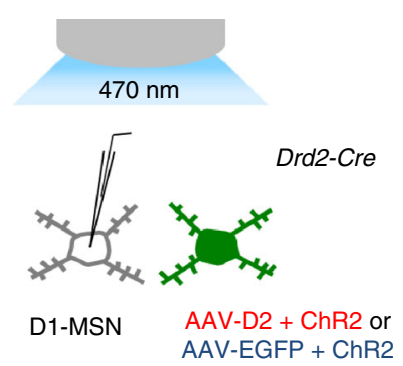

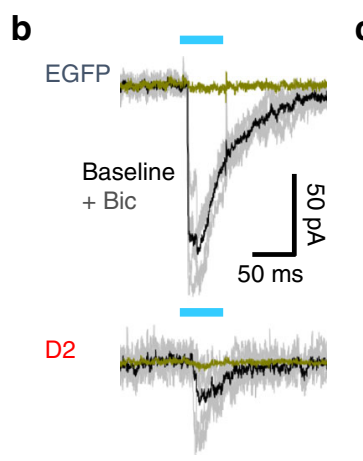

d

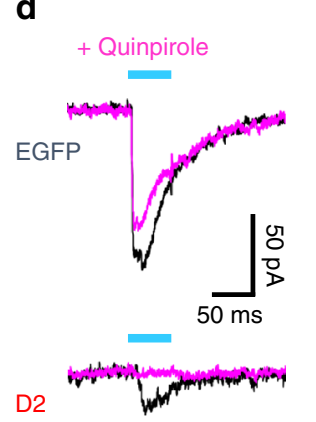

e

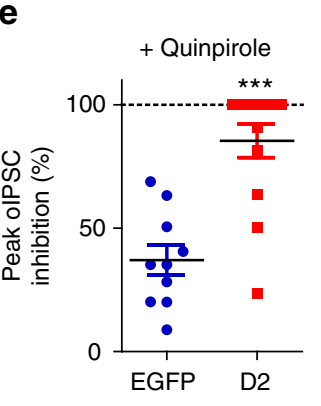

C

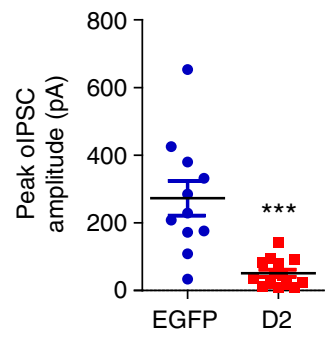

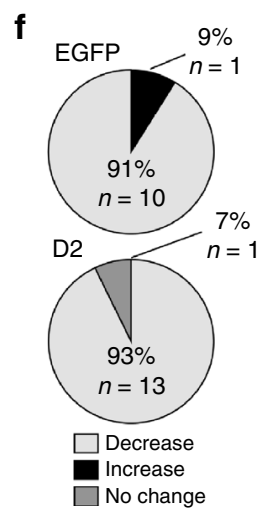

g

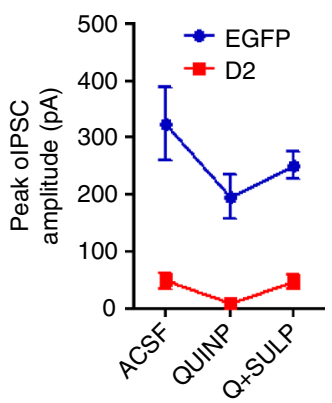

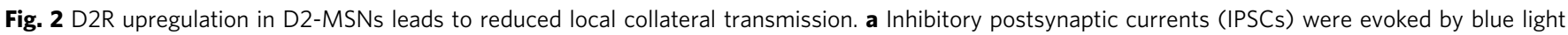
illumination of MSNs co-expressing ChR2 and D2R or ChR2 and EGFP in NAc slices. olPSCs were recorded from neighboring non-fluorescent MSNs. $\mathbf{b}$ Individual (gray) and average (black) traces olPSC traces (gray) from representative MSNs following five 50-ms light pulses (1 Hz). Bicuculline (10 $\mu$ M) eliminated the oIPSC. c Peak oIPSC amplitude under basal conditions was significantly reduced when D2Rs were overexpressed in D2-MSNs $[n=11$ cells (6 mice) or 14 cells (9 mice)]. d, e Treatment with quinpirole ( $1 \mu \mathrm{M})$ reduced olPSC amplitude in both groups, though to a greater extent in D2R-OE mice $[n=10$ cells ( 6 mice) or 14 cells ( 9 mice)]. $\mathbf{f}$ Quinpirole showed an inhibitory effect on olPSC amplitude in $>90 \%$ of cells recorded in both groups. $\mathbf{g}$ Sulpiride co-treatment $(1 \mu \mathrm{M})$ reversed the effect of quinpirole on peak olPSC amplitude $[n=7$ cells $(4 \mathrm{mice})$ or $11 \mathrm{cells}(8 \mathrm{mice})]$. Error bars $=\mathrm{s} . \mathrm{e} . \mathrm{m}$. 
inhibition was much greater in the D2R-OE $\mathrm{NAcInd}_{\text {mice }}(85.4 \pm$ $6.8 \%$ vs. $37.1 \pm 6.1 \%$ in EGFP controls; $t=5.105, p<0.0001)$ (Fig. 2d-f). When the D2R antagonist sulpiride $(1 \mu \mathrm{M})$ was coapplied with quinpirole in a subset of cells that had been treated with quinpirole alone, the oIPSC amplitude was reversed to near basal levels in both groups (Fig. 2g). Together, these results suggest that D2R upregulation in D2-MSNs reduces collateral inhibition of D1-MSNs.

The enhanced quinpirole-mediated effect on oIPSC size observed in D2R-OE $\mathrm{NAcInd}_{\text {mice }}$ is consistent with enhanced presynaptic inhibition of GABA release mediated by activation of a greater number of presynaptic D2Rs. However, it remains unclear whether pre- or postsynaptic mechanisms are responsible for the basal reduction in oIPSC amplitude in D1-MSNs of these mice. D1-MSN intrinsic membrane properties and excitability

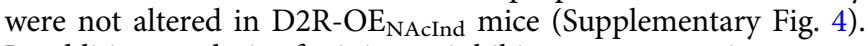
In addition, analysis of miniature inhibitory postsynaptic currents (mIPSCs) in D1-MSNs revealed no significant effects of D2R upregulation on either mIPSC frequency or amplitude (Supplementary Fig. 5). However, in the slice preparation, inhibitory events onto MSNs are derived, to a great extent, from striatal interneurons ${ }^{45}$, so these measurements may not be sufficiently sensitive to detect changes in the collateral inputs from indirect pathway neurons.

Therefore, to achieve greater input-specificity, we replaced extracellular $\mathrm{Ca}^{2+}$ with strontium $\left(\mathrm{Sr}^{2+}\right)$ and recorded from D1MSNs following optogenetic stimulation of D2-MSNs (Supplementary Fig. 6). Under these conditions, $\mathrm{Sr}^{2+}$ leads to desynchronization of neurotransmitter release in terminals recently invaded by an action potential, generating asynchronous IPSCs (asIPSCs) that can be measured for several hundred milliseconds after the initial stimulus ${ }^{46}$. This technique has been used to directly assess postsynaptic efficacy (asIPSC amplitude) and, indirectly, presynaptic function or number of synaptic contacts (asIPSC frequency) in specific basal ganglia circuits ${ }^{46-48}$. We found that in this paradigm, D2R upregulation resulted in significantly decreased mean asIPSC amplitude and frequency even after normalization to the amplitude of the oIPSC (Supplementary Fig. 6). Together, these data suggest that the basal decrease in inhibitory transmission observed in D2R$\mathrm{OE}_{\mathrm{NacInd}}$ mice is due both to pre- and postsynaptic alterations, without associated changes in excitability or global inhibitory input.

In vivo D1-MSN activity is not altered by $\mathrm{D} 2 \mathrm{R}$ upregulation. We hypothesized that reduced collateral inhibition onto D1MSNs might enhance direct pathway activity and thereby contribute to the increase in motivation. To this end, we expressed either DIO-D2R-ires-mCherry or DIO-mCherry in NAc D2MSNs in Drd2-Cre mice, while simultaneously expressing the genetically encoded $\mathrm{Ca}^{2+}$ sensor GCaMP6f in D1-MSNs using a Cre-OFF FAS system ${ }^{49}$ (Fig. 3a). We verified that the FASGCaMP6f construct was targeted to non-Cre expressing cells in Drd2-Cre mice (Fig. 3b). A microendoscopic lens was implanted above the viral injection site to image putative D1-MSN $\mathrm{Ca}^{2+}$ activity during the PR task (Fig. 3c).

We recorded $\mathrm{Ca}^{2+}$ activity in a $5-$ min period in the PR test that encompasses the ratios with the highest press rates in both groups. First, we determined whether D2R upregulation was associated with changes in basal $\mathrm{Ca}^{2+}$ activity in D1-MSNs. We used the constrained non-negative matrix factorization framework modified for microendoscopes (CNMF-E) to localize neurons and extract denoised and demixed $\mathrm{Ca}^{2+}$ signals in our recordings ${ }^{50}$. We reliably detected low frequency, high amplitude $\mathrm{Ca}^{2+}$ transients, as reported in other studies of $\mathrm{Ca}^{2+}$ activity in
$\mathrm{MSNs}^{51}$ (Fig. 3c-e). D2R upregulation, however, did not result in significant changes in the average frequency of $\mathrm{Ca}^{2+}$ transients (mCherry: $0.069 \pm 0.006 \mathrm{~Hz}$; D2: $0.082 \pm 0.002 \mathrm{~Hz} ; t=1.97, p=$ $0.12, n=3$ mice/group) (Fig. 3f). Similar results were obtained when the threshold for transient detection was increased to 2 or 3 S.D. above baseline activity (2 S.D.: mCherry: $0.032 \pm 0.002 \mathrm{~Hz}$; D2: $0.035 \pm 0.001 \mathrm{~Hz} ; t=1.73, p=0.16$; 3 S.D.: mCherry: $0.021 \pm$ $0.001 \mathrm{~Hz} ; \mathrm{D} 2: 0.021 \pm 0.001 \mathrm{~Hz} ; t=0.383, p=0.72 ; n=3$ mice $/$ group). In addition, we sought to determine whether changes in $\mathrm{Ca}^{2+}$ signals were temporally associated with specific behavioral events during PR, such as lever pressing or reward approach. While we observed no clear relationship between $\mathrm{Ca}^{2+}$ activity and lever pressing (not shown), our analyses revealed that head entries into the reward port were associated with changes in $\mathrm{Ca}^{2+}$ activity, but only in a small number of D1-MSNs (Supplementary Fig. 7). Because these event-related changes in $\mathrm{Ca}^{2+}$ signals were not consistently observed across all rewards retrieved by one mouse and because they showed large variability within groups, no quantitative comparisons were drawn. Similar results were obtained when mice were run on a different food incentive operant task (FR5) (mCherry: $0.098 \pm 0.007 \mathrm{~Hz}$; D2: $0.118 \pm$ $0.011 \mathrm{~Hz} ; t=1.405, p=0.203, n=4-5$ mice/group) (Supplementary Fig. 8). These in vivo data suggest that D2R upregulation in D2-MSNs does not result in increased D1-MSN activity during the periods of highest responding in PR or in FR5.

Accumbens D2Rs reduce inhibition of ventral pallidal neurons. D2-MSNs in the NAc core send extensive projections to the ventral pallidum. We used an optogenetic approach similar to that used for the intra-NAc collaterals to test whether D2R upregulation in D2-MSNs reduces inhibitory transmission to the VP. We co-expressed ChR2 with either D2R or EGFP in NAc core D2MSNs. Four weeks later, we recorded from VP neurons within dense, virus-positive terminal fields in slices of the dorsolateral VP (Fig. $4 \mathrm{a}, \mathrm{b}$ ), the primary target area of the NAc core ${ }^{27}$. This slice preparation did not include NAc (or D2-MSN cell bodies), allowing for selective light-evoked stimulation of D2-MSN terminals. Within the VP, we recorded oIPSCs from neurons with the characteristics described for putative GABAergic type B neurons in rat VP slices ${ }^{52,53}$ including spontaneous spiking, slow ramp-like depolarization preceding short duration spikes, and prominent afterhyperpolarization (Fig. 4c). The intrinsic properties of VP neurons recorded from both groups were comparable (resting membrane potential: EGFP, $-46.5 \pm 1.3 \mathrm{mV}, n=11$ cells; D2, $-49.8 \pm 2.0, n=13$ cells; $t=1.3, p=0.21$; input resistance $=$ EGFP, $317.1 \pm 45.3 \mathrm{M} \Omega, n=11$ cells; D2, $590.7 \pm 172.6, n=13$ cells; $t=1.4, p=0.17)$. We found that $\mathrm{D} 2 \mathrm{R}$ upregulation in $\mathrm{D} 2$ MSNs led to an approximately $65 \%$ reduction in oIPSC amplitude compared to controls after photostimulation of ChR2-positive D2MSN terminals in the VP (Fig. 4d, e; $t=2.448, p<0.05, n=$ EGFP: 13(10), D2: 11(7) cells/group). Under our stimulation conditions, we found that quinpirole $(1 \mu \mathrm{M})$ had a bidirectional

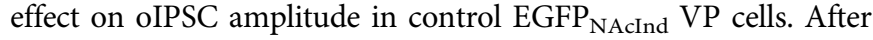
quinpirole, $55 \%$ of control VP neurons showed an attenuated response, whereas $45 \%$ showed an enhanced oIPSC (Fig. 4f and Supplementary Fig. 9). In contrast, quinpirole decreased oIPSC

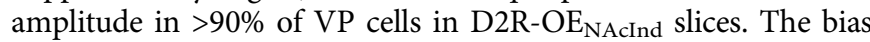
towards decreased oIPSCs in response to quinpirole in D2R$\mathrm{OE}_{\mathrm{NAcInd}} \mathrm{VP}$ cells suggests that additional presynaptic D2Rs play an inhibitory role in regulating GABAergic transmission between NAc D2-MSNs and VP. Co-treatment with sulpiride $(1 \mu \mathrm{M})$ reversed the oIPSC to near basal levels (Fig. $4 \mathrm{~g}$ and Supplementary Fig. 9). Similar effects on oIPSC amplitude under basal conditions and following quinpirole were observed using light pulses of shorter duration (1 ms) (Supplementary Fig. 10). 
a

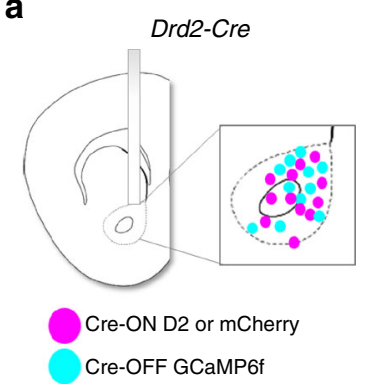

C

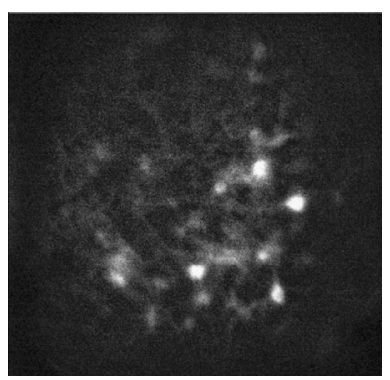

e

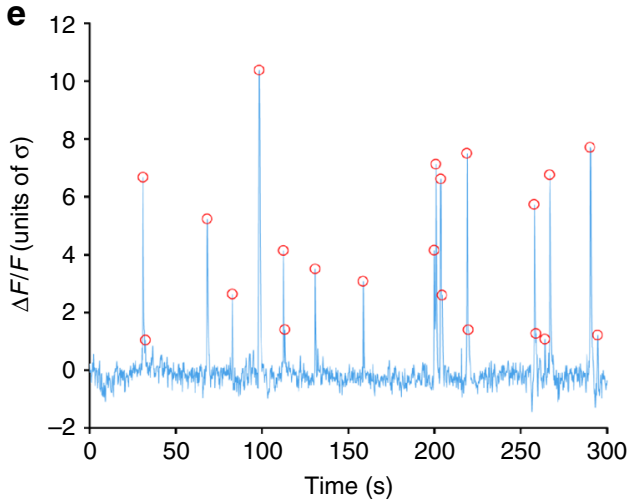

b

d
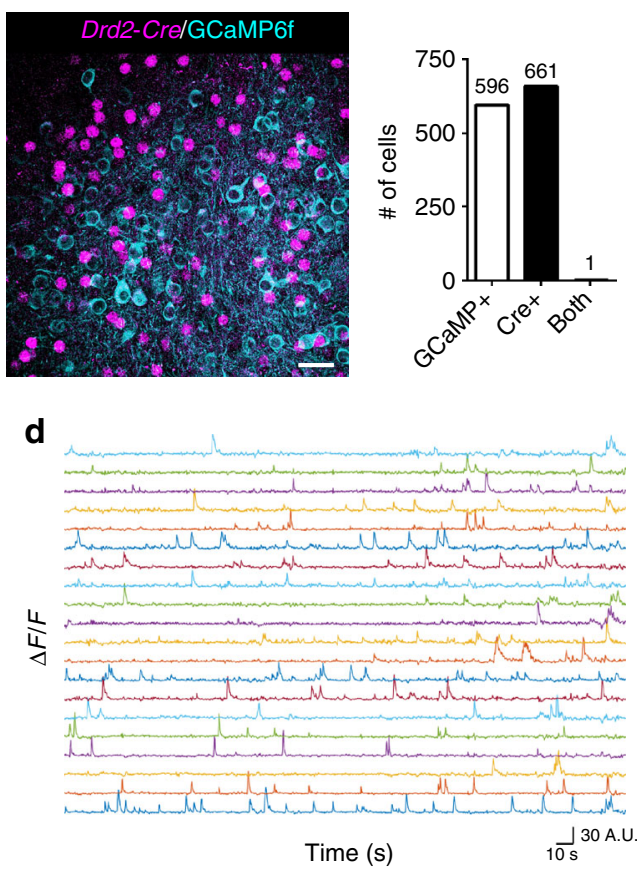

f

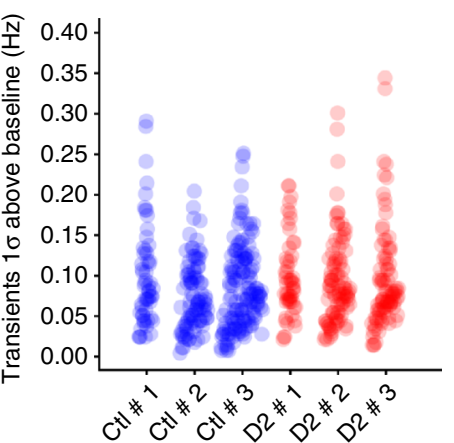

Fig. 3 D2R upregulation in D2-MSNs does not alter D1-MSN activity in vivo. a Schematic of GRIN lens lowered into the NAc core of Drd2-Cre mice transduced with a Cre-ON D2-IRES-mCherry or mCherry in Cre (+) cells (primarily expressed in D2-MSNs) and a Cre-OFF GCaMP6f in Cre (-) cells (primarily expressed in D1-MSNs). b Double immunofluorescence analysis against Cre and GFP shows that in a Drd2-Cre mouse, Cre-OFF GCaMP6f (cyan) expression is restricted to $\mathrm{Cre}(-)$ cells. Scale $=25 \mu \mathrm{m}$. c Representative fluorescent image from live D1-MSNs expressing Cre-OFF GCaMP6f. $\mathbf{d}$ Individual neural $\mathrm{Ca}^{2+}$ transient traces from D1-MSNs in one representative mouse during progressive ratio task. $\mathrm{ea}^{2+}$ transients were defined as events with peak amplitudes greater than 1 standard deviation (S.D.) from baseline activity for analysis. Red circles denote transients whose amplitudes are above 1S.D.

f Frequency of $\mathrm{Ca}^{2+}$ transients recorded during PR from individual cells in 3 mice per group

Inhibition of pallidal activity is reduced by D2Rs in vivo. We extended these findings from slice preparations by asking whether D2R upregulation also affects VP inhibition in an in vivo model in which cortico-basal ganglia loops remain intact. The medial prefrontal cortex (mPFC) exerts both excitatory and inhibitory regulation of VP neurons (Fig. 5a). Activation of the mPFC excites VP neurons directly through glutamatergic projections from the mPFC, as well as indirectly via the subthalamic nucleus ${ }^{54-56}$. It also leads indirectly to inhibition of VP neuron activity through its activation of NAc GABAergic projection neurons $55,57,58$. We hypothesized that, by decreasing D2-MSN output to VP, D2R upregulation in NAc D2-MSNs would decrease the inhibitory response of VP neurons to $\mathrm{mPFC}$ stimulation, while leaving the excitatory response unaffected (Fig. 5b). We performed single unit recordings in the VP of anesthetized D2R-OE $\mathrm{NAcInd}_{\text {and }} \mathrm{EGFP}_{\mathrm{NAcInd}}$ mice during electrical stimulation of mPFC (Fig. 5a, b). VP neuronal responses were assessed using peristimulus histograms (PSTHs) for 50 stimulus trials $(0.2 \mathrm{~ms}$ pulse, $0.5 \mathrm{~Hz}$ ) (Fig. $5 \mathrm{c}-\mathrm{f})$. To assess patterns in PSTHs, responses were first quantified using two-sample Kolmogorov-Smirnov (K-S) tests. While mPFC stimulation typically induced an excitation-inhibition response in VP neurons in $\mathrm{EGFP}_{\mathrm{NAcInd}}$ mice, VP neurons in $\mathrm{D} 2 \mathrm{R}-\mathrm{OE}_{\mathrm{NAcIn}}$ mice generally lacked the inhibitory response (K-S test: $0.25 \mathrm{~mA}: Z=1.13$, $p=0.15$; $0.5 \mathrm{~mA}: Z=1.70, p<0.01 ; 0.75 \mathrm{~mA}: Z=2.08, p<0.01$; $1.0 \mathrm{~mA}: D=2.08, p<0.01)$. VP neuronal responses were further quantified using $Z$ score analysis, which revealed a significant current and genotype interaction (Fig. 5g) (EGFP ${ }_{\text {NAcInd }}$ mice: $F_{\text {current }} \quad[1,4]=35.2, \quad p<0.01 ; \quad$ D2R-OE NAcInd $_{\text {mice: }}$ $F_{\text {current }}[1,4]=15.4, \quad p=0.02 ; \quad F_{\text {genotype } \times \text { current } \quad[1,8]}=44.34$, $p<0.01)$. Thus, both ex vivo and in vivo results provide evidence for reduced indirect pathway-mediated inhibition of VP neurons as a consequence of $\mathrm{D} 2 \mathrm{R}$ upregulation in accumbal D2MSNs. 
a

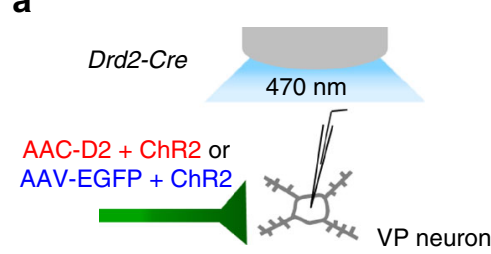

d

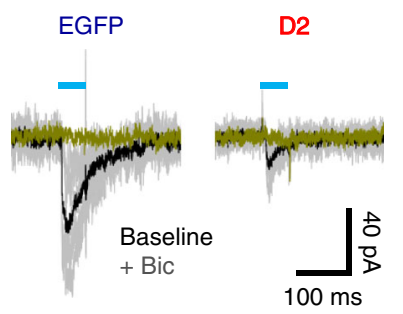

e

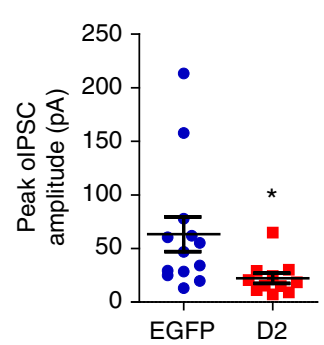

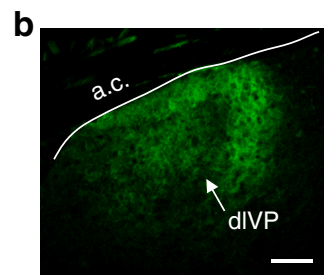

$\mathbf{f}$

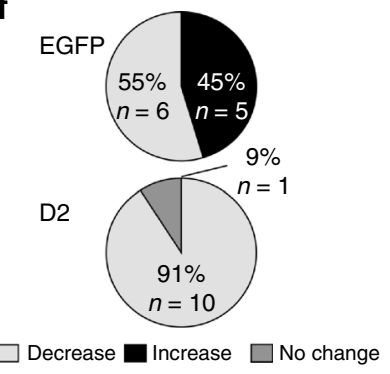

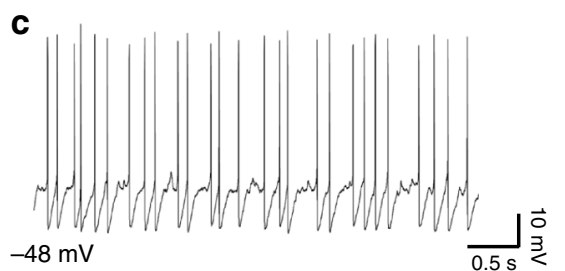

g

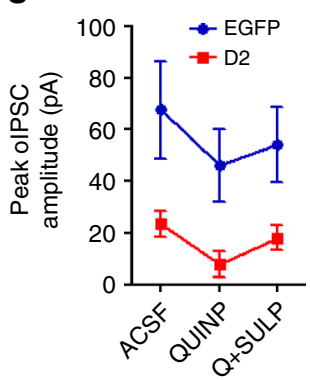

Fig. 4 D2R upregulation reduces D2-MSN inhibitory transmission to ventral pallidum (VP). a Schematic of olPSCs recordings from VP neurons in slice following blue-light stimulation of terminal fields from NAc MSNs co-expressing ChR2 and D2R or ChR2 and EGFP. b VP neurons were recorded from within virus-positive NAc D2-MSN terminal fields in the dorsolateral VP (dIVP). Scale bar $=150 \mu \mathrm{m}$. c Target neurons in VP typically displayed spontaneous firing activity, depolarized RMP, slow ramp-like depolarization preceding short duration spikes, and prominent afterhyperpolarization. d Individual (gray) and average (black) oIPSC traces (gray) from representative MSNs following five 50-ms light pulses $(1 \mathrm{~Hz})$. Bicuculline $(10 \mu \mathrm{M})$ eliminated the oIPSC. e Peak oIPSC amplitude under basal conditions was significantly reduced when D2Rs were overexpressed in D2-MSNs MSNs $[n=13$ cells (10 mice) or 11 cells ( 7 mice)]. f Quinpirole $(1 \mu \mathrm{M})$ bidirectionally modulated olPSCs recorded in $\mathrm{EGFP}_{\mathrm{NAclnd}} \mathrm{VP}$ neurons MSNs $[n=11$ cells $(9$ mice) or 10 cells ( 6 mice)]. In contrast, quinpirole decreased the olPSC amplitude in $>90 \%$ of cells recorded in D2R-OE agonist and antagonist are highlighted by the overall effect of quinpirole and quinpirole + sulpiride $(1 \mu \mathrm{M})$ on olPSC amplitude. Error bars $=$ s.e.m.

Inhibiting accumbopallidal transmission enhances motivation. Our slice electrophysiology results reported above are consistent with an inhibitory role of D2Rs located on D2-MSN terminals in VP. We therefore examined whether inhibition of D2-MSN synaptic transmission to the VP represents the neuronal mechanism by which D2R upregulation enhances motivation. We first co-expressed the DREADD hM4Di-which like D2R is $\mathrm{G}_{\mathrm{i} / \mathrm{o}}$

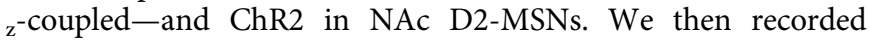
oIPSCs in VP slices containing virus-positive D2-MSN terminals in the presence or absence of CNO (Fig. 6a). Similar to the inhibitory effects of quinpirole in $\mathrm{D} 2 \mathrm{R}-\mathrm{OE}_{\mathrm{NAcInd}}$ mice, lightevoked IPSCs were significantly diminished by CNO $(10 \mu \mathrm{M})$ in all VP neurons recorded $(t=4.284, p<0.005)$ (Fig. 6b, c), as observed by Bock et $\mathrm{al}^{31}$. This suggests that $\mathrm{G}_{\mathrm{i} / \mathrm{o} / \mathrm{z}}$-activation in D2-MSN terminals reduces GABAergic output onto VP neurons.

We then tested whether $\mathrm{G}_{\mathrm{i} / \mathrm{o} / \mathrm{z}}$-mediated inhibition of D2-MSN projections innervating the VP alters PR performance. To this end, we bilaterally expressed hM4Di-mCherry in D2-MSNs of the NAc and implanted microinfusion bilateral cannulae targeting the mCherry-positive terminal fields in the caudal aspect of the dorsolateral VP (Fig. 6d, e and Supplementary Fig. 11). All mice underwent 2 PR sessions, prior to which they received local, bilateral microinfusions of $\mathrm{CNO}$ or saline $(0.3 \mu \mathrm{l} / \mathrm{side})$ in a counterbalanced fashion. Survival function analysis revealed a significant CNO effect on the percentage of mice that continued to respond as session time elapsed (Log-rank test, $\chi^{2}=7.244, p<$ 0.001) (Fig. 6f). CNO also led to a significant increase in total session duration compared to saline treatment $(t=3.54, p=$ $0.005, n=16 /$ group) (Fig. 6g). In addition, the number of presses and the breakpoint were significantly enhanced (presses: $t=3.054$, $p<0.01$; breakpoint: $t=3.128, p<0.01, n=16$ /group) (Fig. 6h, i), while press rate was unaltered (Fig. 6j). CNO injection did not enhance motivation in the absence of hM4D expression (Supplementary Fig. 12). These results indicate that inhibition of the D2-MSN projections just within the VP is sufficient to enhance motivation.

\section{Discussion}

We have found that selective upregulation of D2Rs in the indirect pathway of the NAc increases motivated behavior. This is associated with decreased inhibitory transmission to two main D2MSN targets, neurons in the ventral pallidum and MSNs of the direct pathway. In vivo, D2R upregulation was associated with decreased inhibition of the VP, but not of putative D1-MSNs. Moreover, inhibition of synaptic transmission from D2-MSNs to the VP is sufficient to enhance motivation. Our data therefore suggest that D2R upregulation promotes motivated behavior by weakening the canonical indirect pathway projections to the VP.

Earlier studies using lesions or localized infusions of GABA agonists or antagonists into the VP have shown the importance of this region in motivated behavior ${ }^{59}$. Moreover, local injections of the GABA agonist muscimol into the subthalamic nucleus (STN), one synapse downstream of the VP, enhanced PR performance ${ }^{60}$. Thus, we propose that disinhibition of the VP as achieved by D2R upregulation in NAc D2-MSNs or by increased $G_{i / o}$ signaling via hM4Di activation in D2-MSN terminals, may invigorate PR performance, in part, through a reduction of STN function.

Our results also implicate altered local collateral inhibition of the direct pathway as a mechanism by which D2R upregulation enhances motivation. Studies using paired recordings or optogenetic tools have shown significant functional connectivity between MSNs in the striatum ${ }^{38,40-44,61}$. Generally, D2-MSNs have a stronger influence on D1-MSNs than D1-MSNs on D2$\mathrm{MSNs}^{43}$. Here, we observed collateral inhibition from D2-MSNs to virus-negative MSNs, which in the NAc core are enriched in D1-MSNs of the direct pathway. This collateral inhibition was strongly reduced in $\mathrm{D} 2 \mathrm{R}-\mathrm{OE}_{\mathrm{NAcInd}}$ mice.

However, despite these findings in the slice preparation, using in vivo $\mathrm{Ca}^{2+}$ imaging during the PR task, we found no significant 
a

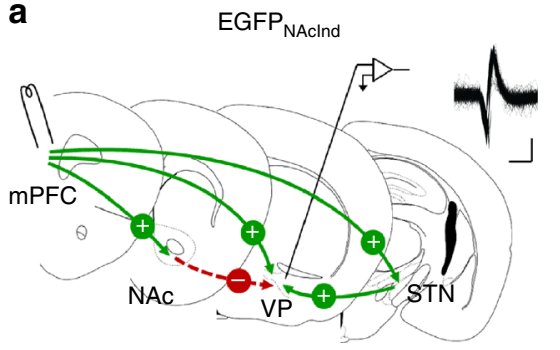

b

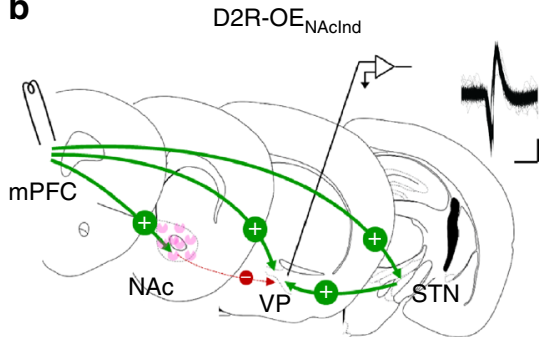

C

$0.25 \mathrm{~mA}$

d
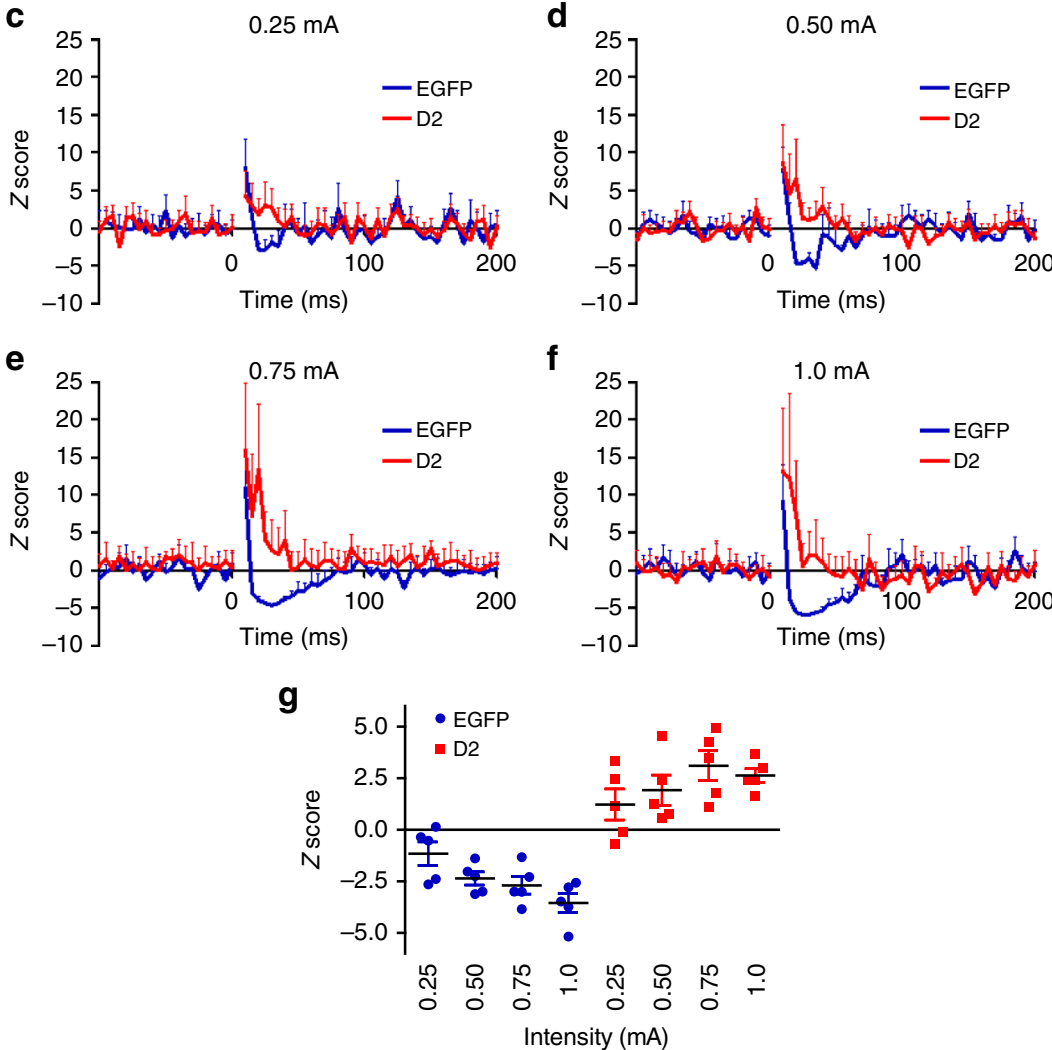

Fig. $5 \mathrm{D} 2 \mathrm{R}$ upregulation is associated with reduced mPFC-evoked inhibition of ventral pallidal neurons in vivo. $\mathbf{a}$, $\mathbf{b}$ Schematic depictions of the stimulating electrode in the medial prefrontal cortex (mPFC) and the recording electrode in the VP in anesthetized mice. mPFC stimulation can lead to excitation of VP neurons directly or via the subthalamic nucleus (STN). mPFC stimulation also leads to inhibitory responses in VP by activation of NAc GABAergic projection neurons. Solid green arrows and $(+)$ sign depict excitatory projections, while the dotted red arrow and (-) sign represent inhibitory projections. Insets, representative VP spike waveforms from recorded cells (overlay of $\sim 500$ spikes; scale $=1.0 \mathrm{~ms}, 0.1 \mathrm{mV}$ ) are consistent with those of GABAergic neurons. We hypothesized that, in contrast to EGFP controls (a), additional D2Rs (pink) in NAc D2-MSNs would attenuate cortically-evoked inhibition of VP (b). c-f $Z$ score transformed peristimulus time histograms (PSTHs) showing mPFC-evoked responses in all recorded VP neurons at different stimulation intensities. Electrical stimulation of the mPFC resulted in an excitation-inhibition response in the VP in the EGFP NAclnd $_{\text {mice. }}$ VP neurons in D2R-OE $_{N A c I n d}$ mice generally lacked the inhibitory response. $\mathbf{g}$ Change in firing rate during the $75 \mathrm{~ms}$ following mPFC stimulation expressed as a $Z$ score of the prestimulation firing rate distribution. Basal firing rates were not different between the two groups $\left(E_{G F P} P_{N A I n d}\right.$ mice: 8.83[1.67] Hz; $D 2 R-O E_{N A c I n d}$ mice: 11.18 [2.08] Hz, $t_{22}=-0.83, p=0.42$ ). EGFP $_{\text {NAclnd: }} n=10$ (5) units, D2R-OE $\mathrm{NAclnd}_{\mathrm{N}}: n=14$ (5) units. Error bars $=$ s.e.m.

effect of D2R upregulation on D1-MSN activity. This suggests that a reduction in D2-MSN-to-D1-MSN transmission is not sufficient to alter overall activity of direct pathway neurons during tasks of incentive motivation, thus arguing against disinhibition of D1-MSNs as a principal mechanism underlying the increase in motivation seen following D2R upregulation. It is possible that the role of D2Rs in lateral inhibition between D2 and D1-MSNs, however, is more behaviorally relevant in settings of high dopamine release, as in the behavioral response to psychostimulants $^{61}$.

D1-MSNs of the NAc also send projections to the VP in addition to their well-known projections to the midbrain ${ }^{29}$, analogous to striatopallidal D1 "bridging" collaterals in the dorsal striatum $^{22}$. These projections might also play a role in regulating motivation. However, our in vivo analysis did not identify alterations in D1-MSN activity, suggesting that this pathway may not be affected in D2R-OE $\mathrm{NacInd}_{\text {mice. }}$

Our slice physiology results show that D2R upregulation in D2-MSNs leads to a profound reduction in light-evoked inhibitory transmission to both local and distal targets via two mechanisms. First, we observed pre- and postsynaptic adaptations that reduce the basal strength of these connections. Acute sulpiride (D2R antagonist/inverse agonist) failed to restore the

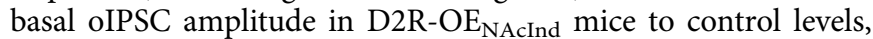
arguing against ambient dopamine or constitutive activity of the D2Rs in the slice as a mediator of the inhibition of synaptic 
a

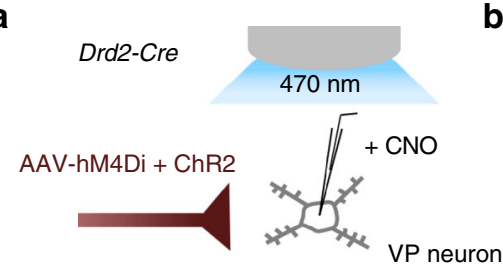

b

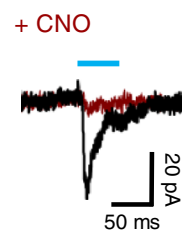

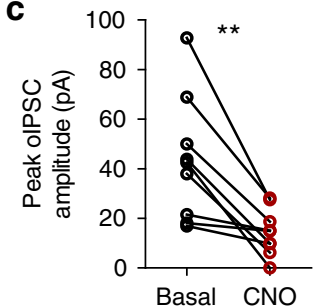

d
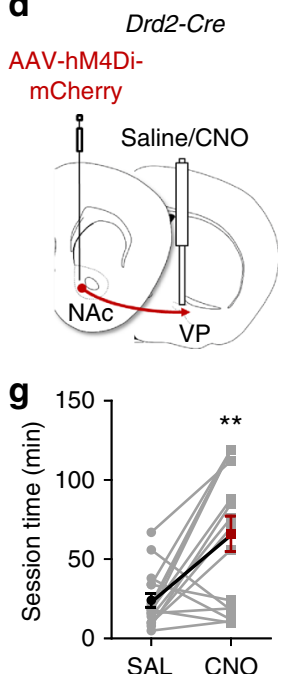

e
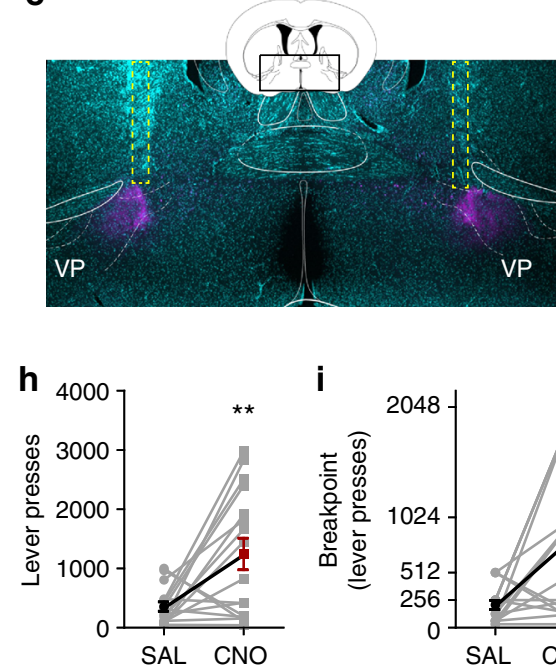

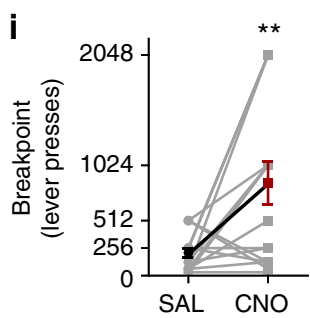

f

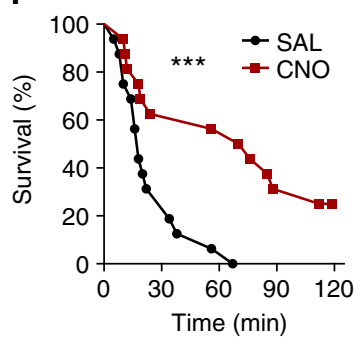

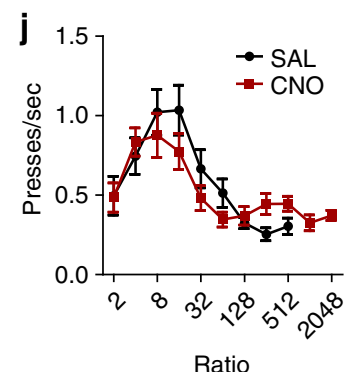

Ratio

Fig. 6 DREADD-mediated silencing of D2-MSN terminals in the VP enhances motivation. a Schematic illustrating olPSC recording from VP neurons in slice following CNO $(10 \mu \mathrm{M})$ treatment and blue-light stimulation of terminal fields from NAc MSNs co-expressing ChR2 and hM4Di. b Representative average oIPSC traces following 50-ms light stimulation under basal conditions (black) and after CNO application (dark red). c CNO significantly reduced olPSC amplitude from baseline ( $14.5 \pm 3.1$ from $43.6 \pm 8.3 \mathrm{pA}$; ${ }^{* \star} p<0.005$, paired Student's $t$-test, $n=9$ (6) cells). d Drd2-Cre mice were injected hM4Di-mCherry AAV into the NAc, and a bilateral microinfusion cannula guide was implanted. Four weeks after surgery, an internal cannula was briefly inserted into the guide to deliver CNO $(1 \mathrm{mM}, 0.3 \mu \mathrm{l} / \mathrm{side})$ or saline to the caudal VP prior to PR testing. All 16 mice received both treatments on different days in counterbalanced fashion. e Representative fluorescent Nissl stain (green) showing the location of bilateral microinfusion cannula tracks (yellow dotted lines) relative to hM4Di-mCherry immunofluorescent terminal fields (red) in the caudal aspect of the VP. Inset, coronal atlas plane ( $+0.02 \mathrm{~mm}$ relative to Bregma) from which image was acquired. $\mathbf{f}$, $\mathbf{g}$ Significant enhancing effect of CNO microinfusion on session duration plotted as a survival function or as total session time ( $n=16$ mice/condition). $\mathbf{h}$, i Lever presses and breakpoint were significantly increased after CNO ( $n=16$ mice/condition). $\mathbf{j}$ Press rate as a function of ratio requirement was not altered by $\mathrm{CNO}$. Error bars $=$ s.e.m.

transmission. The strontium experiments revealed a reduction in both the frequency and amplitude of asIPSCs that was independent of the initial stimulus strength. These data, therefore, point to changes both at the level of presynaptic release (or number of synaptic contacts), and at the level of postsynaptic efficacy. Defining the precise mechanisms underlying these synaptic adaptations in basal D2-MSN output will be of interest for further investigation.

Second, acute treatment with the D2R agonist quinpirole attenuated light-evoked inhibitory currents in the NAc, an effect that was enhanced in $\mathrm{D} 2 \mathrm{R}-\mathrm{OE}_{\mathrm{NacInd}}$ mice. This enhancement is likely due to decreased presynaptic function mediated by increased D2R levels, consistent with reports of acute presynaptic effects of quinpirole or dopamine on MSN-MSN or MSNpallidum transmission ${ }^{37-40,61}$. Application of CNO to hM4Diexpressing D2-MSNs also resulted in acute attenuation of oIPSC in VP neurons, similar to the inhibitory effect of quinpirole in

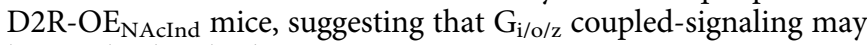
be involved in both cases.

In our experiments, light-evoked IPSCs at D2-MSN to D1MSN synapses were more sensitive to quinpirole-mediated inhibition than at striatopallidal synapses in $\mathrm{EGFP}_{\text {NAcInd }}$ mice, in agreement with other reports ${ }^{61}$. Over $90 \%$ of D2-to-D1-MSN
oIPSCs were reduced by quinpirole whereas only $55 \%$ of striatopallidal oIPSCs transmission were reduced by the D2 agonist. Surprisingly, quinpirole increased the oIPSC in $45 \%$ of VP cells. The interpretation of the quinpirole effect is complicated by the fact that inhibition within the pallidum is also mediated by intrapallidal connections of GABAergic neurons ${ }^{62}$, some of which also express D2/D3/D4 receptors ${ }^{56,63-65}$. Indeed, in vivo studies measuring VP firing rates after iontophoretic application of quinpirole found that about $24 \%$ of VP neurons increased their firing rates as expected but $15 \%$ of VP neurons decreased their firing rates ${ }^{66}$. This bidirectional effect may be due to D2-like receptors expressed within the VP. In D2R-OE $\mathrm{NAcInd}_{\text {mice, where }}$ D2Rs are selectively increased in D2-MSNs of the NAc, the balance was altered and the oIPSC were reduced in $90 \%$ of neurons in the presence of quinpirole. This suggests that presynaptic D2Rs at ventral striatopallidal terminals inhibit neurotransmission, as proposed in the $\mathrm{GPe}^{37,39}$. Besides showing enhanced quinpirolemediated inhibition of oIPSC in VP slices containing no NAc neurons, $\mathrm{D} 2 \mathrm{R}-\mathrm{OE}_{\mathrm{NAcInd}}$ mice displayed robust viral-mediated D2R immunofluorescence in D2-MSN terminal fields innervating the VP, further supporting a presynaptic role for D2Rs. In this respect, ultrastructural studies in VP have shown that most D2Rpositive axon terminals are GABAergic ${ }^{65}$. Although a role for 
dopamine modulation of VP activity has been consistently reported, the role of presynaptic D2R function in the VP is less well understood, likely due to a lack of cell-type specific approaches ${ }^{56}$. Here, we provide new evidence linking D2Rs specifically found in afferent D2-MSN terminals to VP neuron activity.

A recent study reported that optogenetic inhibition of the NAc indirect pathway led to a decrease in progressive ratio performance ${ }^{67}$, whereas here decreasing indirect pathway function enhances motivation. However, there are important differences between both studies in the site of inhibition (unilateral versus bilateral inhibition), in the time window of inhibition (10 s vs. the entire session), and in the design of the task (inhibition of activity during a cue that signals the onset of the trial versus no explicit cue). It is therefore possible that the indirect pathway may have opposite functions regarding motivation depending on whether it is active during a cue signaling later reward or during the sustained process of working in the form of lever pressing. Moreover, unlike neuronal inhibition during a discrete time point in the task $\mathrm{k}^{67}$, our approach is designed to turn up the gain for endogenously released dopamine acting on indirect pathway D2Rs.

Higher D2R levels in ventral striatum have been linked to higher trait motivation in ADHD and better treatment outcomes for drug abusers ${ }^{10,68}$. However, it has been unclear how altered D2R function affects ventral striatal circuitry and behavior. Here we show that selective D2R upregulation in indirect pathway MSNs is sufficient to invigorate motivated behavior by decreasing indirect pathway output. While our cell-selective D2R upregulation in the mouse is not intended to model a specific disorder, it has helped to provide mechanistic insight into the role of NAc D2Rs in motivation. This should have clinical relevance since D2R binding is altered in brain disorders with altered motivation $^{9-15}$. Our results suggest that D2R-based or related strategies for decreasing ventral striatopallidal transmission may have the potential to advance therapies for reversing motivational deficits across multiple brain disorders. In particular, the adenosine $\mathrm{A}_{2 \mathrm{~A}}$ receptor $\left(\mathrm{A}_{2 \mathrm{~A}} \mathrm{R}\right)$ has been proposed as a promising therapeutic target for the motivational symptoms of depression ${ }^{69} . \mathrm{A}_{2 \mathrm{~A}} \mathrm{Rs}$ are co-expressed with D2Rs in indirect pathway MSNs and are thought to oppose D2R function ${ }^{70}$. Indeed, $\mathrm{A}_{2 \mathrm{~A}} \mathrm{R}$ antagonism within the NAc has been shown to enhance motivated behavior in rats $^{69,71}$. Our results suggest that the mechanisms by which $A_{2 A} R$ antagonists increase motivation may involve increased $D 2 R$ function in D2-MSNs, and thus a weakening of indirect pathway output.

\begin{abstract}
Methods
Mice. Adult male and female Drd2-Cre (ER44; GENSAT), Drd2-Cre/D1-tdTomato (B6.Cg-Tg(Drdla-tdTomato)6Calak/J; Jackson); ChAT-Cre (GM60; GENSAT) backcrossed onto C57BL/6 J background were used in experiments. Mice were housed 3-5 per cage for most experiments or individually for $\mathrm{Ca}^{2+}$ imaging experiments, on a $12 \mathrm{~h}$ light/dark cycle. All experiments were conducted in the light cycle. All experimental procedures were conducted following $\mathrm{NIH}$ guidelines and were approved by Institutional Animal Care and Use Committees by Columbia University and New York State Psychiatric Institute.
\end{abstract}

Surgical procedures. Mice ( $\geq 8$ weeks old) were bilaterally injected with a previously characterized Cre-dependent double-inverted open reading frame (DIO) adenoassociated viruses (AAVs) encoding D2R-ires-Venus ${ }^{19}$, EGFP, ChR2-EYFP, hM3Dq-mCherry, or hM4Di-mCherry (UNC Vector Core, Chapel Hill, NC) into the nucleus accumbens (NAc) using stereotactic Bregma-based coordinates: ${ }^{73} \mathrm{AP}$, $+1.70 \mathrm{~mm} ; \mathrm{ML}, \pm 1.20 \mathrm{~mm}$; DV, $-4.1 \mathrm{~mm}$ (from dura). Groups of mice used for experiments were first assigned their AAV-genotype in a counterbalanced fashion that accounted for sex, age, home cage origin. For cannula-guided microinfusion experiments, mice were implanted in caudal VP with a bilateral guide cannula (AP, $+0.12 \mathrm{~mm} ; \mathrm{ML}, \pm 1.5 \mathrm{~mm}$; DV,$-2.5 \mathrm{~mm}$ (from dura) at the time of AAV surgery. On test days, following brief restraint of the mice, dummy cannulae were removed and internal cannulae (33 G) with a $2 \mathrm{~mm}$ projection were inserted into guide to achieve a final depth of $-4.5 \mathrm{~mm}$. The guide cannulae (26 G; Plastics One, Roanoke,
VA) were anchored with machine microscrews and fixed in place with dental cement. Dummy cannulae were placed into the guide and protected with a dust cap. For $\mathrm{Ca}^{2+}$ imaging of NAc, a $0.5 \mathrm{~mm}$ craniotomy was made at the following coordinates: AP: $+1.7 \mathrm{~mm}$, ML: $+1.2 \mathrm{~mm}$ (right side). Brain tissue was then carefully aspirated by lowering aspiration needle at a rate $0.1 \mathrm{~mm} / \mathrm{min}$ until a depth of $-2.4 \mathrm{~mm}$ (from skull surface). After aspiration, a 1:1 mix of AAV-DIO-mCherry (Addgene) or AAV-DIO-D2-IRES-mCherry AAV and a Cre-OFF AAV-FASGCaMP6f (constructed in-house using pAAV-Ef1a-FAS-hChR2(H134R)mCherry-WPRE-pA from Bernardo Sabatini and produced at Vector Biolabs) was bilaterally injected (AP: $+1.7 \mathrm{~mm}, \mathrm{ML}: \pm 1.2 \mathrm{~mm}$, DV: $-4.2,-4.1$, and $-4.0 \mathrm{~mm}$; $0.22 \mu \mathrm{l}$ at each depth). A $0.5 \mathrm{~mm}$ diameter gradient index (GRIN) lens affixed to an imaging cannula (Doric Lenses, Inc.) was then carefully lowered through same skull opening to $\mathrm{D} / \mathrm{V}$ : $-4.1 \mathrm{~mm}$. Lens cannula was anchored with machine microscrews and fixed in place with dental cement. Mice were imaged 5-6 weeks after cannula implantation.

Operant apparatus. Eight operant chambers (model Env-307w; Med-Associates, St. Albans, VT) equipped with liquid dippers were used. Each chamber was located in a light- and sound-attenuating cabinet equipped with an exhaust fan, which provided $72-\mathrm{dB}$ background white noise in the chamber. The dimensions of the experimental chamber interior were $22 \times 18 \times 13 \mathrm{~cm}$, with flooring consisting of metal rods placed $0.87 \mathrm{~cm}$ apart. A feeder trough was centered on one wall of the chamber. An infrared photocell detector was used to record head entries into the trough. Raising of the dipper inside the trough delivered a drop of evaporated milk reward. A retractable lever was mounted on the same wall as the feeder trough, 5 $\mathrm{cm}$ away. A house light located on wall opposite to trough illuminated the chamber throughout all sessions.

Dipper and lever press training. Four weeks after AAV surgery, mice underwent operant training. Mice were weighed daily and food-restricted to $85-90 \%$ of baseline weight; water was available ad libitum. In the first training session, 20 dipper presentations were separated by a variable inter-trial interval (ITI) and ended after 20 rewards were earned or after $30 \mathrm{~min}$ had elapsed, whichever occurred first. Criterion consisted of the mouse making head entries during 20 dipper presentations in one session. In the second training session, criterion was achieved when mice made head entries during 30 of 30 dipper presentations. For lever press training, lever presses were reinforced on a continuous reinforcement (CRF) schedule. Levers were retracted after each reinforcer and were presented again after a variable ITI (average $30 \mathrm{~s}$ ). The reward consisted of raising the dipper for $5 \mathrm{~s}$. The session ended when the mouse earned 60 reinforcements, or one hour elapsed, whichever occurred first. Sessions were repeated daily until mice achieved 60 reinforcements.

Fixed interval (FI) training. In FI training, lever presses were reinforced until after a fixed interval (timed relative to the lever extension) had elapsed. Each reinforcement was followed by a variable inter-trial interval (average $30 \mathrm{~s}$ ) during which the lever remained retracted, and then a new trial started, signaled by lever extension. Mice began with FI-4 s session and proceeded successively to longer interval sessions after earning $\geq 30$ rewards in each session. The FI durations were $4,8,12,16$, and $24 \mathrm{~s}$.

Progressive ratio (PR) and fixed ratio (FR) tasks. Mice underwent operant training 4 weeks after surgery followed by PR. In PR, a reward was obtained after the mice made the required number of lever presses. The criterion was set at two lever presses for the first trial and the requirement doubled with each successive trial. The session ended after $2 \mathrm{~h}$ or after $3 \mathrm{~min}$ had elapsed without a lever press Breakpoint was defined as the last criterion successfully completed. Mean values from 3 PR sessions were analyzed. For hM4Di experiments, CNO $(0.3 \mu \mathrm{l}, 1 \mathrm{mM}$ in saline) or saline was delivered bilaterally to VP via cannula-based microinfusions using a Hamilton syringe and a microdrive motor at a rate of $0.05 \mu \mathrm{l} / \mathrm{min}$. At the end of each infusion, the internal cannula was left in place for $15 \mathrm{~min}$ to ensure diffusion, and mice were tested on PR task 5 min after removing the internal and replacing the dummy. Each mouse received one infusion of saline and one of $\mathrm{CNO}$, 3 days apart. Investigators were blind to genotype of mice during the experiment, and the order of the infusions was counterbalanced between groups, matched for age and sex. Mice had two intervening RR5 sessions in the days between each PR test.

Concurrent choice task. For this task, we used random ratio (RR) schedules, which involve a constant probability of reinforcement for each lever press and assess effort in instrumental responding ${ }^{18}$. The mice were first trained for 3 days in 30 min RR5 sessions. Animals were then tested in concurrent RR/choice procedure. This task consisted of having 8-12 $\mathrm{g}$ of lab chow freely available in a dish in the operant chamber while the mouse performed the RR schedule. Increasing ratios with and without chow were used (RR5, RR10, RR20, RR40, RR80, RR120). One animal was excluded from the data analysis because of lever pressing extinction. 
Slice preparation and whole-cell patch clamp recording. Four weeks after surgery, brains were harvested into ice-cold, oxygenated ACSF containing (in $\mathrm{mM}$ ): $1.25 \mathrm{NaH}_{2} \mathrm{PO}_{4}, 2.5 \mathrm{KCl}, 10$ glucose, $26.2 \mathrm{NaHCO}_{3}, 126 \mathrm{NaCl}, 2 \mathrm{CaCl}_{2}$ and $2 \mathrm{MgCl}_{2}$ ( $\mathrm{pH} 7.4,300-310 \mathrm{mOsm})$. Coronal striatal slices $(300 \mu \mathrm{m})$ were cut on a vibratome in ice-cold, oxygenated ACSF and incubated at $32{ }^{\circ} \mathrm{C}$ for $30 \mathrm{~min}$ followed by $1 \mathrm{~h}$ at room temperature before recording. Voltage- and current-clamp whole-cell recordings were performed using standard techniques at room temperature. Electrodes were pulled from $1.5 \mathrm{~mm}$ borosilicate-glass pipettes on a P-97 puller (Sutter Instruments). Electrode resistance was $\sim 4-6 \mathrm{M} \Omega$ when filled with internal solution consisting of (in mM): $130 \mathrm{~K}^{+}$-Gluconate, $5 \mathrm{NaCl}, 10$ HEPES, 0.5 EGTA, 2 $\mathrm{Mg}^{+}$-ATP, and $0.3 \mathrm{Na}^{+}$-GTP (pH 7.3, $280 \mathrm{mOsm}$ ). Whole-cell patch-clamp recordings were obtained with a Multiclamp $700 \mathrm{~B}$ amplifier, digitized at $10 \mathrm{kHz}$ using a Digidata $1440 \mathrm{~A}$ acquisition system with Clampex 10, and analyzed with pClamp 10 (Molecular Devices). Only cells that maintained a stable access resistance $(<30 \mathrm{M} \Omega)$ throughout the entire recording were analyzed. GFP/Venus or tdTomato positive MSNs within the NAc core were identified under IR-DIC optics and epifluorescence microscopy. Current-voltage and input-output (spike frequency) curves were obtained from injecting $500 \mathrm{~ms}$ currents ranging from -150 to $+340 \mathrm{pA}$ in $10 \mathrm{pA}$ steps. Spiking frequency $(\mathrm{Hz})$ was determined from the initial pair of action potentials ${ }^{72}$. mIPSCs were isolated by adding TTX $(1 \mu \mathrm{M}), \mathrm{D}$-AP5 $(50 \mu \mathrm{M})$, and CNQX $(20 \mu \mathrm{M})$ in ACSF while recording at a holding potential of $-80 \mathrm{mV}$ and measured over a period of $6 \mathrm{~min}$ using Synaptosoft Mini Analysis software. To enhance detection of mIPSCs, we used high $\mathrm{Cl}^{-}$internal solution, consisting of (in mM): $136.5 \mathrm{KCl}, 10$ HEPES, 0.5 EGTA, $2 \mathrm{Mg}^{+}$-ATP, and $0.3 \mathrm{Na}^{+}$-GTP (pH 7.3, $280 \mathrm{mOsm}$ ). Light-evoked IPSC experiments were done at $\mathrm{RT}$ at $-80 \mathrm{mV}$ in the presence of D-AP5 $(50 \mu \mathrm{M})$ and CNQX $(20 \mu \mathrm{M})$. oIPSCs were evoked with five 1 -ms or 50 -ms light pulses $(470 \mathrm{~nm}, 1 \mathrm{~Hz}, 2.3 \mathrm{~mW})$ using field illumination through a $\times 40$ objective with a PE-100 CoolLED illumination system (Olympus). High $\mathrm{Cl}^{-}$internal solution, as shown above, was used to enhance detection of oIPSCs. We blocked oIPSCs using $10 \mu \mathrm{M}$ bicuculline. Peak amplitudes of oIPSCs were measured from averages of five individual traces. Slices were treated for 5 min with quinpirole hydrochloride $(1 \mu \mathrm{M})$, sulpiride $(1 \mu \mathrm{M})$ or clozapine $\mathrm{N}$ oxide $(10 \mu \mathrm{M})$. To measure asynchronous IPSCs, recordings were conducted at $32^{\circ}$ $\mathrm{C}$ in extracellular solution containing $2 \mathrm{mM} \mathrm{Sr}^{2+}\left(0 \mathrm{mM} \mathrm{Ca}^{2+}\right)$, D-AP5 $(50 \mu \mathrm{M})$ and CNQX $(20 \mu \mathrm{M})$, while holding at $-70 \mathrm{mV}$. Internal solution was as for mIPSC solution with substitution of $\mathrm{KCl}$ with $136.5 \mathrm{mM} \mathrm{CsCl}$ and the addition of $2 \mathrm{mM}$ QX-314 hydrobromide. Ten trials using a 5-ms blue light pulse $(0.6 \mathrm{~Hz})$ were used to activate ChR2-positive terminals and generate asIPSCs. Detection of asIPSCs occurred within the $50-500 \mathrm{~ms}$ period after the stimulus ${ }^{47}$. asIPSCs were detected if greater than 2 S.D. above noise using Synaptosoft MiniAnalysis software, and the amplitude of each event was measured from a local baseline $5 \mathrm{~ms}$ before the start of peak to avoid decaying transient artifacts associated with residual synchronous release $^{46}$.

In vivo single unit recordings. Mice anesthetized with chloral hydrate were implanted with a stimulating electrode (Tungsten concentric, Microprobes) for electrical stimulation of the mPFC (AP + 1.9, ML $\pm 0.3, \mathrm{DV}-2.0)$. A glass electrode (impedance 12-14 M $\Omega$ ) filled with $2 \mathrm{M} \mathrm{NaCl}$ was lowered into the VP (AP $-0.1, \mathrm{ML} \pm 1.5, \mathrm{DV}-4.0$ ) using a hydraulic microdrive to detect spontaneously active pallidal neurons. From this starting point, the VP was sampled in four locations $0.15 \mathrm{~mm}$ apart and arranged in a $2 \times 2$ spaced grid. The starting locations were counterbalanced across animals and groups. Pallidal neurons were identified using a combination of stereotaxic position and narrow action potential width $(<1$ $\mathrm{ms}$ ). After 2-3 min of stable recording, electrical stimulation (50 pulses, $0.2 \mathrm{~ms}$ pulse width, $0.5 \mathrm{~Hz}$ ) was applied at $0.25,0.5,0.75$, and $1.0 \mathrm{~mA}$ current intensities. Neuronal activity was amplified and filtered $(1000 \times$ gain, $100-10 \mathrm{KHz}$ band pass) and fed to an audio monitor and to a computer interface with custom-designed acquisition and analysis software (Neuroscope). Peri-stimulus time histograms (PSTHs) were obtained by sampling spike frequency with $5 \mathrm{~ms}$ bins $200 \mathrm{~ms}$ before, during and $200 \mathrm{~ms}$ after electrical stimulation. Spike frequencies in the PSTHs were expressed as $Z$ scores expressed as a function of baseline firing during the $200 \mathrm{~ms}$ preceding electrical stimulation. Average firing rate over the first $75 \mathrm{~ms}$ following electrical stimulation was then compared between the 2 groups.

In vivo calcium imaging. For $\mathrm{Ca}^{2+}$ imaging experiments, mice were habituated to a dummy microscope and cables during final phases of FI training. Prior to PR test, a Doric Lenses snap-in microscope was attached to the imaging cannula under brief isoflurane anesthesia. Ten minutes after full recovery, mice were placed in operant chamber to begin PR session. Image acquisition was done at $10 \mathrm{~Hz}$, triggered by presentation of the 3rd reward (completion of ratio 8) and lasting for 5 consecutive minutes, and was conducted over 2 daily PR sessions. This period was chosen because it generally showed the highest press rates, generated more than 1 reward, and showed no difference in responding between groups. FR5 sessions, in which mice must make 5 presses to earn a reward, were conducted similarly over 5 min, but with image acquisition starting at session onset.

Image stacks collected using the microendoscope imaging system were registered using Doric Neuroscience Studio Image Analysis software. Each stack was then imported into the CNMF-E framework as previously described ${ }^{50}$. CNMF$\mathrm{E}$ was used to locate neurons and extract raw $\mathrm{Ca}^{2+}$ fluorescence values over time. Neural $\mathrm{Ca}^{2+}$ transients were defined as events whose $\Delta F / F$ peak amplitudes were greater than 1 standard deviation above the baseline fluorescence. Custom MATLAB functions and scripts were used to import and analyze MedPC (MedAssociates) behavioral data corresponding to each of the fluorescence traces.

Histology. Mice were transcardially perfused with ice-cold $4 \%$ paraformaldehyde (Sigma, St. Louis, MO) in PBS under deep anesthesia. Brains were harvested, postfixed overnight and washed in PBS. Free-floating 30- $\mu \mathrm{m}$ coronal sections were obtained using a Leica VT2000 vibratome (Richmond, VA). After incubation in blocking solution (10\% fetal bovine serum, $0.5 \%$ bovine serum albumin in $0.5 \%$ TBS-Triton X-100) for $1 \mathrm{~h}$ at room temperature, sections were labeled overnight at $4{ }^{\circ} \mathrm{C}$ with primary antibodies against $\mathrm{GFP} / \mathrm{mVenus/GCaMP6f}$ (chicken; 1:1000; AB13970 Abcam, Cambridge, MA); D2R (rabbit; 1:500; in-house); Cre (rabbit, 1:2000; in-house ${ }^{74}$ ); and DsRed (rabbit; 1:250; 632496, Clontech, Mountain View, CA) to label mCherry. Sections were incubated with fluorescent secondary antibodies for $1 \mathrm{~h}$ at RT followed by, in some cases, incubation in Neurotrace green fluorescent Nissl stain according to manufacturer's protocol (Life Technologies, Grand Island, NY). Sections were then mounted on slides and coverslipped with Vectashield containing DAPI (Vector, Burlingame, CA). Digital images were acquired using a Nikon epifluorescence microscope, or with a Leica SP8 scanning confocal microscope, and processed with NIH Image J and Adobe Photoshop software.

Data analysis. Sample sizes were determined by performing statistical power analyses based on effect sizes observed in preliminary data or on similar work in the literature. Statistical analyses were performed using Graphpad Prism 5.01. Data are expressed as mean \pm SEM. Paired and unpaired two-tailed Student's $t$-tests were used to compare 2-group data, as appropriate. Multiple comparisons were evaluated by one-way or two-way ANOVA and Bonferroni's post hoc test, when appropriate. Log-rank tests were used to analyze survival curves. A $p$-value of $<0.05$ was considered statistically significant. Behavioral and electrophysiological findings were successfully replicated with mice from different litters, ages, or sexes, and in several instances, across independent cohorts or related mouse strains. In addition, evoked electrophysiology responses were replicated using different stimulus intensities in vitro and in vivo, and data was collected from several animals.

Code availability. Custom code used to generate results that are reported in the paper will be made available upon reasonable request.

Data availability. The data that support the findings of this study are available from the corresponding author upon reasonable request.

Received: 28 November 2017 Accepted: 1 February 2018 Published online: 14 March 2018

\section{References}

1. Buckley, P. F. \& Stahl, S. M. Pharmacological treatment of negative symptoms of schizophrenia: therapeutic opportunity or cul-de-sac? Acta Psychiatr. Scand. 115, 93-100 (2007).

2. Gard, D. E., Fisher, M., Garrett, C., Genevsky, A. \& Vinogradov, S. Motivation and its relationship to neurocognition, social cognition, and functional outcome in schizophrenia. Schizophr. Res. 115, 74-81 (2009).

3. Salamone, J. D., Correa, M., Farrar, A. \& Mingote, S. M. Effort-related functions of nucleus accumbens dopamine and associated forebrain circuits. Psychopharmacology 191, 461-482 (2007).

4. Berridge, K. C. The debate over dopamine's role in reward: the case for incentive salience. Psychopharmacology 191, 391-431 (2007).

5. Aberman, J. E., Ward, S. J. \& Salamone, J. D. Effects of dopamine antagonists and accumbens dopamine depletions on time-constrained progressive-ratio performance. Pharmacol. Biochem. Behav. 61, 341-348 (1998).

6. Kelley, A. E., Baldo, B. A., Pratt, W. E. \& Will, M. J. Corticostriatalhypothalamic circuitry and food motivation: integration of energy, action and reward. Physiol. Behav. 86, 773-795 (2005).

7. Phillips, P. E., Walton, M. E. \& Jhou, T. C. Calculating utility: preclinical evidence for cost-benefit analysis by mesolimbic dopamine. Psychopharmacology 191, 483-495 (2007).

8. Carvalho Poyraz, F. et al. Decreasing striatopallidal pathway function enhances motivation by energizing the initiation of goal-directed action. $J$. Neurosci. 36, 5988-6001 (2016).

9. Volkow, N. D., Fowler, J. S., Wang, G. J., Baler, R. \& Telang, F. Imaging dopamine's role in drug abuse and addiction. Neuropharmacology 56, 3-8 (2009)

10. Volkow, N. D. et al. Motivation deficit in ADHD is associated with dysfunction of the dopamine reward pathway. Mol. Psychiatry 16, 1147-1154 (2011). 
11. Martinez, D. et al. Alcohol dependence is associated with blunted dopamine transmission in the ventral striatum. Biol. Psychiatry 58, 779-786 (2005).

12. Heinz, A. et al. Correlation between dopamine $\mathrm{D}(2)$ receptors in the ventral striatum and central processing of alcohol cues and craving. Am. J. Psychiatry 161, 1783-1789 (2004).

13. Laruelle, M. Imaging dopamine transmission in schizophrenia. A review and meta-analysis. Q. J. Nucl. Med. 42, 211-221 (1998).

14. Abi-Dargham, A. et al. Increased baseline occupancy of D2 receptors by dopamine in schizophrenia.[comment]. Proc. Natl Acad. Sci. USA 97, 8104-8109 (2000).

15. Howes, O. D. et al. The Nature of Dopamine Dysfunction in Schizophrenia and What This Means for Treatment: Meta-analysis of Imaging Studies. Arch. Gen. Psychiatry 66, 13-20 (2012).

16. Treadway, M. T. et al. Dopaminergic mechanisms of individual differences in human effort-based decision-making. J. Neurosci. 32, 6170-6176 (2012).

17. Tomer, R., Goldstein, R. Z., Wang, G. J., Wong, C. \& Volkow, N. D. Incentive motivation is associated with striatal dopamine asymmetry. Biol. Psychol. 77, 98-101 (2008).

18. Trifilieff, P. et al. Increasing dopamine D2 receptor expression in the adult nucleus accumbens enhances motivation. Mol. Psychiatry 18, 1025-1033 (2013).

19. Gallo, E. F. et al. Upregulation of dopamine D2 receptors in the nucleus accumbens indirect pathway increases locomotion but does not reduce alcohol consumption. Neuropsychopharmacology 40, 1609-1618 (2015).

20. Gerfen, C. R. \& Surmeier, D. J. Modulation of striatal projection systems by dopamine. Annu. Rev. Neurosci. 34, 441-466 (2011).

21. Fujiyama, F. et al. Exclusive and common targets of neostriatofugal projections of rat striosome neurons: a single neuron-tracing study using a viral vector. Eur. J. Neurosci. 33, 668-677 (2011).

22. Cazorla, M. et al. Dopamine D2 receptors regulate the anatomical and functional balance of basal ganglia circuitry. Neuron 81, 153-164 (2014).

23. Albin, R. L., Young, A. B. \& Penney, J. B. The functional anatomy of basal ganglia disorders. Trends Neurosci. 12, 366-375 (1989).

24. Kravitz, A. V. et al. Regulation of parkinsonian motor behaviours by optogenetic control of basal ganglia circuitry. Nature 466, 622-626 (2010).

25. Cui, G. et al. Concurrent activation of striatal direct and indirect pathways during action initiation. Nature 494, 238-242 (2013).

26. Zahm, D. S. The ventral striatopallidal parts of the basal ganglia in the rat--II. Compartmentation of ventral pallidal efferents. Neuroscience 30, 33-50 (1989).

27. Heimer, L., Zahm, D. S., Churchill, L., Kalivas, P. W. \& Wohltmann, C. Specificity in the projection patterns of accumbal core and shell in the rat. Neuroscience 41, 89-125 (1991).

28. Ikemoto, S. Dopamine reward circuitry: two projection systems from the ventral midbrain to the nucleus accumbens-olfactory tubercle complex. Brain Res. Rev. 56, 27-78 (2007).

29. Kupchik, Y. M. et al. Coding the direct/indirect pathways by D1 and D2 receptors is not valid for accumbens projections. Nat. Neurosci. 18, 1230-1232 (2015).

30. Hikida, T., Kimura, K., Wada, N., Funabiki, K. \& Nakanishi, S. Distinct roles of synaptic transmission in direct and indirect striatal pathways to reward and aversive behavior. Neuron 66, 896-907 (2010).

31. Bock, R. et al. Strengthening the accumbal indirect pathway promotes resilience to compulsive cocaine use. Nat. Neurosci. 16, 632-638 (2013).

32. Durieux, P. F. et al. D2R striatopallidal neurons inhibit both locomotor and drug reward processes. Nat. Neurosci. 12, 393-395 (2009).

33. Lobo, M. K. et al. Cell type-specific loss of BDNF signaling mimics optogenetic control of cocaine reward. Science 330, 385-390 (2010).

34. Herlitze, S. et al. Modulation of $\mathrm{Ca} 2+$ channels by G-protein beta gamma subunits. Nature 380, 258-262 (1996).

35. Ikeda, S. R. Voltage-dependent modulation of N-type calcium channels by Gprotein beta gamma subunits. Nature 380, 255-258 (1996).

36. Martel, P., Leo, D., Fulton, S., Berard, M. \& Trudeau, L. E. Role of Kv1 potassium channels in regulating dopamine release and presynaptic D2 receptor function. PLoS ONE 6, e20402 (2011).

37. Cooper, A. J. \& Stanford, I. M. Dopamine D2 receptor mediated presynaptic inhibition of striatopallidal GABA(A) IPSCs in vitro. Neuropharmacology 41, 62-71 (2001)

38. Tecuapetla, F., Koos, T., Tepper, J. M., Kabbani, N. \& Yeckel, M. F. Differential dopaminergic modulation of neostriatal synaptic connections of striatopallidal axon collaterals. J. Neurosci. 29, 8977-8990 (2009).

39. Floran, B., Floran, L., Sierra, A. \& Aceves, J. D2 receptor-mediated inhibition of GABA release by endogenous dopamine in the rat globus pallidus. Neurosci. Lett. 237, 1-4 (1997)

40. Kohnomi, S., Koshikawa, N. \& Kobayashi, M. D. (2)-like dopamine receptors differentially regulate unitary IPSCs depending on presynaptic GABAergic neuron subtypes in rat nucleus accumbens shell. J. Neurophysiol. 107, 692-703 (2012)
41. Tunstall, M. J., Oorschot, D. E., Kean, A. \& Wickens, J. R. Inhibitory interactions between spiny projection neurons in the rat striatum. J. Neurophysiol. 88, 1263-1269 (2002).

42. Venance, L., Glowinski, J. \& Giaume, C. Electrical and chemical transmission between striatal GABAergic output neurones in rat brain slices. J. Physiol. 559 , 215-230 (2004).

43. Taverna, S., Ilijic, E. \& Surmeier, D. J. Recurrent collateral connections of striatal medium spiny neurons are disrupted in models of Parkinson's disease. J. Neurosci. 28, 5504-5512 (2008).

44. Chuhma, N., Tanaka, K. F., Hen, R. \& Rayport, S. Functional connectome of the striatal medium spiny neuron. J. Neurosci. 31, 1183-1192 (2011).

45. Wilson, C. J. GABAergic inhibition in the neostriatum. Prog. Brain. Res. $\mathbf{1 6 0}$ 91-110 (2007).

46. Lerner, $\mathrm{T}$. N. et al. Intact-brain analyses reveal distinct information carried by snc dopamine subcircuits. Cell 162, 635-647 (2015).

47. MacAskill, A. F., Cassel, J. M. \& Carter, A. G. Cocaine exposure reorganizes cell type- and input-specific connectivity in the nucleus accumbens. Nat. Neurosci. 17, 1198-1207 (2014).

48. Britt, J. P. et al. Synaptic and behavioral profile of multiple glutamatergic inputs to the nucleus accumbens. Neuron 76, 790-803 (2012).

49. Saunders, A. \& Sabatini, B. L. Cre activated and inactivated recombinant adeno-associated viral vectors for neuronal anatomical tracing or activity manipulation. Curr. Protoc. Neurosci. 72, 1.24.21-15 (2015).

50. Pnevmatikakis, E. A. et al. Simultaneous denoising, deconvolution, and demixing of calcium imaging data. Neuron 89, 285-299 (2016).

51. Barbera, G. et al. Spatially compact neural clusters in the dorsal striatum encode locomotion relevant information. Neuron 92, 202-213 (2016).

52. Bengtson, C. P. \& Osborne, P. B. Electrophysiological properties of cholinergic and noncholinergic neurons in the ventral pallidal region of the nucleus basalis in rat brain slices. J. Neurophysiol. 83, 2649-2660 (2000).

53. Lavin, A. \& Grace, A. A. Physiological properties of rat ventral pallidal neurons recorded intracellularly in vivo. J. Neurophysiol. 75, 1432-1443 (1996).

54. Maurice, N., Deniau, J. M., Glowinski, J. \& Thierry, A. M. Relationships between the prefrontal cortex and the basal ganglia in the rat: physiology of the corticosubthalamic circuits. J. Neurosci. 18, 9539-9546 (1998).

55. Sesack, S. R., Deutch, A. Y., Roth, R. H. \& Bunney, B. S. Topographical organization of the efferent projections of the medial prefrontal cortex in the rat: an anterograde tract-tracing study with Phaseolus vulgaris leucoagglutinin. J. Comp. Neurol. 290, 213-242 (1989).

56. Root, D. H., Melendez, R. I., Zaborszky, L. \& Napier, T. C. The ventral pallidum: subregion-specific functional anatomy and roles in motivated behaviors. Prog. Neurobiol. 130, 29-70 (2015).

57. Fuller, T. A., Russchen, F. T. \& Price, J. L. Sources of presumptive glutamergic/ aspartergic afferents to the rat ventral striatopallidal region. J. Comp. Neurol. 258, 317-338 (1987).

58. Maurice, N., Deniau, J. M., Menetrey, A., Glowinski, J. \& Thierry, A. M. Position of the ventral pallidum in the rat prefrontal cortex-basal ganglia circuit. Neuroscience 80, 523-534 (1997).

59. Farrar, A. M. et al. Forebrain circuitry involved in effort-related choice: Injections of the GABAA agonist muscimol into ventral pallidum alter response allocation in food-seeking behavior. Neuroscience 152, 321-330 (2008).

60. Baunez, C., Dias, C., Cador, M. \& Amalric, M. The subthalamic nucleus exerts opposite control on cocaine and 'natural' rewards. Nat. Neurosci. 8, 484-489 (2005).

61. Dobbs, L. K. et al. Dopamine regulation of lateral inhibition between striatal neurons gates the stimulant actions of cocaine. Neuron 90, 1100-1113 (2016).

62. Kita, H. Globus pallidus external segment. Prog. Brain Res. 160, 111-133 (2007).

63. Diaz, J. et al. Phenotypical characterization of neurons expressing the dopamine D3 receptor in the rat brain. Neuroscience 65, 731-745 (1995).

64. Noain, D. et al. Identification of brain neurons expressing the dopamine D4 receptor gene using BAC transgenic mice. Eur. J. Neurosci. 24, 2429-2438 (2006).

65. Mengual, E. \& Pickel, V. M. Ultrastructural immunocytochemical localization of the dopamine D2 receptor and tyrosine hydroxylase in the rat ventral pallidum. Synapse 43, 151-162 (2002).

66. Napier, T. C. \& Maslowski-Cobuzzi, R. J. Electrophysiological verification of the presence of D1 and D2 dopamine receptors within the ventral pallidum. Synapse 17, 160-166 (1994).

67. Soares-Cunha, C. et al. Activation of D2 dopamine receptor-expressing neurons in the nucleus accumbens increases motivation. Nat. Commun. 7, 11829 (2016)

68. Martinez, D. et al. Imaging dopamine transmission in cocaine dependence: link between neurochemistry and response to treatment. Am. J. Psychiatry 168, 634-641 (2011).

69. Nunes, E. J., Randall, P. A., Podurgiel, S., Correa, M. \& Salamone, J. D. Nucleus accumbens neurotransmission and effort-related choice behavior in food 
motivation: effects of drugs acting on dopamine, adenosine, and muscarinic acetylcholine receptors. Neurosci. Biobehav. Rev. 37, 2015-2025 (2013).

70. Svenningsson, P., Le Moine, C., Fisone, G. \& Fredholm, B. B. Distribution, biochemistry and function of striatal adenosine A2A receptors. Prog. Neurobiol. 59, 355-396 (1999).

71. Mingote, S. et al. Nucleus accumbens adenosine A2A receptors regulate exertion of effort by acting on the ventral striatopallidal pathway. J. Neurosci. 28, 9037-9046 (2008).

72. Franklin, K. B. J. \& Paxinos, G. The Mouse Brain in Stereotaxic Coordinates 3rd edn, (Academic Press, New York, 2007).

73. Cazorla, M., Shegda, M., Ramesh, B., Harrison, N. L. \& Kellendonk, C. Striatal D2 receptors regulate dendritic morphology of medium spiny neurons via Kir2 channels. J. Neurosci. 32, 2398-2409 (2012).

74. Kellendonk, C. et al. Inducible site-specific recombination in the brain. J. Mol. Biol. 285, 175-182 (1999).

\section{Acknowledgements}

We thank Matthew Bailey for guidance on cannula-guided microinfusions, and Eleanor Simpson for providing microinfusion equipment. We thank Fernanda Carvalho Poyraz and Sarah Canetta for input on the design of behavioral experiments and slice recordings. We also thank Lindsay Kenney, Caroline Rauffenbart, and Celine Laruelle for technical assistance and the Rodent Neurobehavioral Analysis Core at NYSPI for behavior facilities and equipment. Clozapine- $\mathrm{N}$-oxide was obtained from the Rapid Access to Investigative Drug Program (NINDS). This work was supported by NIH grants MH093672 to C.K., MH54137 and DA022413 to J.A.J. MH107648 to E.F.G. and 1P50MH086404 to H.M.

\section{Author contributions}

E.F.G., J.D.S., E.T., M.O.C., and C.S.C. conducted the experiments. E.F.G., J.M., and M.O. C. conducted data analysis. E.F.G., H.M., J.A.J., and C.K. designed the experiments. E.F.G., M.O.C., J.M., and C.K. wrote the paper. H.M. and J.A.J. edited the paper. H.M., J.A.J., and C.K. supervised experiments and data analysis.

\section{Additional information}

Supplementary Information accompanies this paper at https://doi.org/10.1038/s41467018-03272-2.

Competing interests: The authors declare no competing interests.

Reprints and permission information is available online at http://npg.nature.com/ reprintsandpermissions/

Publisher's note: Springer Nature remains neutral with regard to jurisdictional claims in published maps and institutional affiliations.

(c) Open Access This article is licensed under a Creative Commons Attribution 4.0 International License, which permits use, sharing, adaptation, distribution and reproduction in any medium or format, as long as you give appropriate credit to the original author(s) and the source, provide a link to the Creative Commons license, and indicate if changes were made. The images or other third party material in this article are included in the article's Creative Commons license, unless indicated otherwise in a credit line to the material. If material is not included in the article's Creative Commons license and your intended use is not permitted by statutory regulation or exceeds the permitted use, you will need to obtain permission directly from the copyright holder. To view a copy of this license, visit http://creativecommons.org/ licenses/by/4.0/.

(C) The Author(s) 2018 